\title{
Diseases and Molecular Diagnostics: A Step Closer to Precision Medicine
}

\author{
Shailendra Dwivedi ${ }^{1}$ Purvi Purohit ${ }^{1} \cdot$ Radhieka Misra $^{2}$ - Puneet Pareek $^{3}$. \\ Apul Goel ${ }^{4}$ - Sanjay Khattri ${ }^{5} \cdot$ Kamlesh Kumar Pant $^{5} \cdot$ Sanjeev Misra ${ }^{6}$. \\ Praveen Sharma ${ }^{1}$
}

Published online: 22 August 2017

(C) Association of Clinical Biochemists of India 2017

\begin{abstract}
The current advent of molecular technologies together with a multidisciplinary interplay of several fields led to the development of genomics, which concentrates on the detection of pathogenic events at the genome level. The structural and functional genomics approaches have now pinpointed the technical challenge in the exploration of disease-related genes and the recognition of their structural alterations or elucidation of gene function. Various promising technologies and diagnostic applications of structural genomics are currently preparing a large database of disease-genes, genetic alterations etc., by mutation scanning and DNA chip technology. Further the functional genomics also exploring the expression genetics (hybridization-, PCR- and sequence-based technologies), twohybrid technology, next generation sequencing with Bioinformatics and computational biology. Advances in microarray "chip" technology as microarrays have allowed the parallel analysis of gene expression patterns of thousands of genes simultaneously. Sequence information collected
\end{abstract}

Praveen Sharma

praveensharma55@gmail.com

1 Department of Biochemistry, All India Institute of Medical Sciences, Jodhpur 342005, India

2 Era's Lucknow Medical College and Hospital, Lucknow 226003, India

3 Department of Radio-Therapy, All India Institute of Medical Sciences, Jodhpur 342005, India

4 Department of Urology, King George Medical University, Lucknow 226003, India

5 Department of Pharmacology and Therapeutics, King George Medical University, Lucknow 226003, India

6 Department of Surgical Oncology, All India Institute of Medical Sciences, Jodhpur 342005, India from the genomes of many individuals is leading to the rapid discovery of single nucleotide polymorphisms or SNPs. Further advances of genetic engineering have also revolutionized immunoassay biotechnology via engineering of antibody-encoding genes and the phage display technology. The Biotechnology plays an important role in the development of diagnostic assays in response to an outbreak or critical disease response need. However, there is also need to pinpoint various obstacles and issues related to the commercialization and widespread dispersal of genetic knowledge derived from the exploitation of the biotechnology industry and the development and marketing of diagnostic services. Implementation of genetic criteria for patient selection and individual assessment of the risks and benefits of treatment emerges as a major challenge to the pharmaceutical industry. Thus this field is revolutionizing current era and further it may open new vistas in the field of disease management.

Keywords Molecular signature - Molecular techniques . Molecular diagnostics - Genetic diseases and disorders . Precision medicine

\section{Introduction}

Our healthcare system is critically and crucially dependent upon diagnostics. Today's medical decision making is strongly based upon the diagnostics results. Right from the genetic tests that can help notify personalized cancer treatment to the microbial culture for recognition of right antibiotic combating an infection, diagnostics provide critical insights at every stage of medical care prevention, detection, diagnosis, treatment and successful management of health conditions. The main categories of diagnostics are 
clinical chemistry, immunology, hematology, microbiology and molecular diagnostics. The molecular diagnostics has attracted particular attention in recent years owing to deep insights it brings to diagnosis and treatment.

Molecular diagnostics has transformed diagnostics dynamically, leading to insights in research and treatment in many disease states that are revolutionizing health care. The current review will provide an overview of the current scenario of molecular diagnostics, with the glimpse of the key technology that are driving the molecular revolution with pin-pointing some specific diseases and disorders. We conclude by noting emergence of two novel therapeutic approaches of pharmaco-genomics and nutri-genomics that have the power to influence the diseases management plan.

\section{History of Molecular Diagnostics: Advancements and Discovery}

The field of molecular biology grew in the late twentieth century (Table 1). In 1980 [1] advised a prenatal genetic test for Thalassemia that was not based on DNA sequencing, but on restriction enzymes that cut DNA at specific short sequences, creating various bands of DNA strand depending upon the presence of allele (genetic variation). In the 1980s, the term "Molecular Diagnostics" was utilized in the names of companies such as Molecular Diagnostics Incorporated and Bethesda Research Laboratories Molecular Diagnostics [2]. The 1990s saw an era of identification of newly discovered genes and new techniques for DNA sequencing.

Table 1 Historical significance-development and progression of molecular biology/techniques

\begin{tabular}{|c|c|c|c|}
\hline $\begin{array}{l}\text { Year/ } \\
\text { decades }\end{array}$ & Discovery/event & Discoverer/company & Remarks \\
\hline 1869 & Deoxyribonucleic acid, or DNA & Johann Friedrich Miescher & - \\
\hline 1944 & Transforming material is DNA & $\begin{array}{l}\text { Oswald Avery, McCarty and Colin } \\
\text { MacLeod }\end{array}$ & DNA seems to be genetic material \\
\hline 1928 & Transformation & Franklin Griffith & Genetic material is a heat-stable chemical \\
\hline 1949 & DNA composition was species specific & Erwin Chargaff & $\mathrm{A}=\mathrm{T} ; \mathrm{G}=\mathrm{C}$ \\
\hline 1949 & $\begin{array}{l}\text { Characterization of sickle cell anaemia as a } \\
\text { molecular disease }\end{array}$ & Linus Pauling & $\begin{array}{l}\text { Discovery that a single amino acid change at } \\
\text { the } \beta \text {-globin chain leads to sickle cell } \\
\text { anemia }\end{array}$ \\
\hline 1953 & Double helical model of DNA & Watson-Crick & Led the foundation of molecular biology \\
\hline 1958 & Isolation of DNA Polymerases & Arthur Kornberg & Important milestone for DNA replication \\
\hline 1960 & First Hybridization techniques & Roy Britten & - \\
\hline 1969 & In situ-hybridization & Gall and Pardue & \\
\hline 1970, & Isolated the first restriction enzyme & Hamilton Smith & $\begin{array}{l}\text { An enzyme that cuts DNA at a very specific } \\
\text { nucleotide sequence }\end{array}$ \\
\hline 1972 & Assembled the first DNA molecule & Paul Berg & $\begin{array}{l}\text { Crucial steps in the subsequent development } \\
\text { of recombinant genetic engineering }\end{array}$ \\
\hline 1961 & $\begin{array}{l}\text { First "triplet"- - a sequence of three bases } \\
\text { of DNA }\end{array}$ & Marshall Nirenberg & $\begin{array}{l}\text { Triplet-codes for one of the twenty amino } \\
\text { acids }\end{array}$ \\
\hline 1961 & Theory of genetic regulatory mechanisms & François Jacob and Jacques Monod & $\begin{array}{l}\text { Showed on a molecular level, how certain } \\
\text { genes are activated and suppressed }\end{array}$ \\
\hline 1973 & $\begin{array}{l}\text { Efforts to create the construction of } \\
\text { functional organisms }\end{array}$ & Stanley Cohen and Herbert Boyer & $\begin{array}{l}\text { Experiments try to demonstrate the potential } \\
\text { impact of DNA recombinant engineering }\end{array}$ \\
\hline 1977 & $\begin{array}{l}\text { Developed new techniques for rapid DNA } \\
\text { sequencing }\end{array}$ & $\begin{array}{l}\text { Walter Gilbert (with graduate student } \\
\text { Allan M. Maxam) and Frederick } \\
\text { Sanger }\end{array}$ & $\begin{array}{l}\text { Made it possible to read the nucleotide } \\
\text { sequence for entire genes }\end{array}$ \\
\hline 1970s, & $\begin{array}{l}\text { Nucleic acid hybridization methods and } \\
\text { DNA probes }\end{array}$ & - & Highly specific for detecting targets \\
\hline 1983 & Polymerase chain reaction (PCR) & Kary Mullis & For rapidly multiplying fragments of DNA \\
\hline 1985 & $\begin{array}{l}\text { New method to detect patient's beta-globin } \\
\text { gene for diagnosis of sickle cell anaemia }\end{array}$ & Saiki and his colleagues & - \\
\hline 1987 & $\begin{array}{l}\text { Identified human immunodeficiency virus } \\
\text { (HIV) by using PCR method }\end{array}$ & Kwok and colleagues & $\begin{array}{l}\text { The first report the application of PCR in } \\
\text { clinical diagnosis infectious disease }\end{array}$ \\
\hline 1992 & Conception of real time PCR & Higuchi et al. & Amplification in real time \\
\hline 1996 & First application of DNA microarrays & Derisi et al. & DNA arrays to be made on glass substrates \\
\hline 2001 & $\begin{array}{l}\text { First draft versions of the human genome } \\
\text { sequence }\end{array}$ & $\begin{array}{l}\text { International Human Genome } \\
\text { Sequencing Consortium }\end{array}$ & - \\
\hline
\end{tabular}


This led to the emergence of a distinct field of molecular and genomic laboratory medicine; in 1995, the Association for Molecular Pathology (AMP) was formed to give it structure. In 1999, the AMP co-founded The Journal of Medical Diagnostics; Informa Healthcare launched Expert Reviews in Medical Diagnostics in 2001 [3]. From 2002 onwards, the Hap Map Project combined information on the one-letter genetic differences that recur in the human population, as single nucleotide polymorphisms (SNPs) and also pointed their relationship with disease. In 2012, molecular diagnostic techniques for Thalassemia use genetic hybridization tests to recognize the specific SNP causing an individual's disease.

With commercialization of these techniques, debut the patents/exclusive right for their achievements. In 1998, the European Union's Directive 98/44/EC clarified that patents on DNA sequences were allowable. An example of the patents use in molecular diagnostics was seen in 2010 in the US, when AMP sued Myriad Genetics to defy the latter's patents regarding two genes, BRCA1, BRCA2, which are associated with breast cancer. However, in 2013, the US Supreme Court ordered, a ruling that a naturally occurring gene sequence could not be patented.

The term "Molecular disease" was introduced by Pauling and his colleagues in 1949, based on their finding that change in a single amino acid at the $\beta$-globin chain causes sickle cell anaemia. In principle, their explorations have set the foundations of molecular diagnostics, even though the big transformations occurred many years later.

\section{Molecular Diagnostic Techniques in Identification and Characterization}

Correct and accurate identification of causative agents like microbes in microbial diseases, particular genetic sequences in genetic diseases and protein levels are very essential for the management of these patients, making specificity and sensitivity important tools in diagnosis. Classical molecular techniques like normal PCR and blotting although played satisfactory role in diagnosis. However, currently molecular techniques like gene and peptide sequencer, real-time PCR and microarrays may detect more precisely and specifically without consuming much time.

\section{Polymerase Chain Reactions (PCR)}

The discovery of PCR [4] and its quick optimization, by a thermo stable Taq DNA polymerase from Thermus aquaticus [5] has greatly facilitated and revolutionized molecular diagnostics. It is a robust technique as a large amount of copies of the target sequence generated by its exponential amplification, permiting the identification of a known mutation within a single day, rather than months. With the advent of PCR, molecular diagnostics to cross the threshold of the clinical laboratory for the provision of genetic services, such as carrier or population screening for known mutations, prenatal diagnosis of inherited diseases, or in recent years, identification of unknown mutations. Therefore, being moved to their proper environment, the clinical laboratory, and molecular diagnostics could provide the services for which they have been initially considered. Each PCR cycle theoretically doubles the amount of specific DNA sequence present resulting in an exponential accumulation of the DNA fragment being amplified. PCR is an enzyme-driven, primer-mediated (forward and reverse primer), temperature-dependent process for replicating a specific DNA sequence in vitro. The principle of PCR is based on the repetitive cycling of three simple reactions of amplification that include: (1) Denaturing: At $95{ }^{\circ} \mathrm{C}$ template DNA double strand separates into two single strands. (2) Annealing: Next the temperature is reduced to $55^{\circ} \mathrm{C}$ and two specific oligonucleotide primers attach to the DNA template complementarily. (3) Extension: The temperature is then raised again but this time to $72{ }^{\circ} \mathrm{C}$, facilitating the DNA polymerase to extend the primers at the $3^{\prime}$ terminus of each primer and synthesize the complementary strands along $5^{\prime}$ to $3^{\prime}$ terminus of each template DNA using deoxynucleotides contained in media.

Extension leads to formation of new double strand DNA copies comprising of two single template DNA strands and two synthesized complementary DNA strands. After extension, the reaction will repeat above steps. Each copy of DNA then serves as another template for further amplification. PCR products will be doubled in each cycle. After $\mathrm{n}$ cycles (approx. 30), the final PCR products will have double no. copies of template DNA in theory. The whole process just needs $2-5 \mathrm{~h}$ depending on the no. and types of nucleotide.

\section{Multiplex PCR}

Multiplex PCR is like performing multiple PCR reactions simultaneously in single PCR tube. Here two or more primer pairs are included in one reaction tube and two or more DNA templates are targeted simultaneously. It is a relatively effortless molecular way to detect few different bacteria in one PCR reaction. In multiplex PCR, the primer pairs should be specific to the target gene and the PCR products (amplicons) should be in different sizes that are specific to different DNA sequences. This technique saves time and reagents by targeting multiple genes at a time, therefore extra information may be gained from a single test-run that otherwise would require several times the reagents and more time to perform. Annealing 
temperatures for each of the primer sets must be optimized to work correctly within a single reaction, and amplicon sizes. That is, their base pair length should be different enough to form distinct bands when visualized by gel electrophoresis.

\section{Reverse Transcription-Polymerase Chain Reaction (RT-PCR)}

RT-PCR is the technique of synthesis of cDNA from RNA by reverse transcription (RT) firstly, which is then followed with amplification of a specific cDNA by PCR. This is the most valuable and sensitive technique for mRNA detection and quantitation that is currently available. RT-PCR is mostly used to detect viruses and the viability of microbial cells through the assessment of microbial mRNA. The discovery of PCR also has provided the foundations for the design and development of many mutation detection schemes, based on amplified DNA. In general, PCR either is used for the generation of the DNA fragments to be examined, or is part of the recognition method. The first attempt was the use of restriction enzymes [6] or oligonucleotide probes, immobilized onto membranes or in solution [7] in order to spot the existing genetic variation, in particular the sickle cell disease-causing mutation. In the following years, an even larger number of mutation detection approaches have been build up and implemented. RT-PCR may be single step or two step procedure. As the name suggests single step RT-PCR shall combines first-strand cDNA synthesis (RT) and subsequent PCR in a single reaction tube. This technique requires gene specific primer and is useful in high throughput applications. However it is less sensitive and efficient since the reaction is a compromise between reverse transcription and amplification conditions. Two step PCR requires two steps-first one for the synthesis of c-DNA in a PCR tube followed by second step in a separate PCR tube for amplification of gene of interest. This technique is more sensitive, flexible and allows analysis of multiple genes.

\section{Real-Time PCR}

Real time PCR is a simple, quantitative assay for any amplifiable DNA sequence. It was illustrated for the first time by, Higuchi et al. [8]. It is based on using fluorescent labelled probes to detect, confirm, and quantify the PCR products as they are being generated in real time. The real time PCR, which has three novel features as temperature cycling occurs considerable faster than in standard PCR assays, hybridization of specific DNA probes occurs continuously during the amplification reaction and a fluorescent dye is coupled to the probe and fluoresces only when hybridization takes place. Lack of post PCR processing of amplified products makes this technique convenient. The production of amplified products is observed automatically by real time monitoring of fluorescence. Depending on the amount of target gene, a small signal can be produced within 30-45 min. Since the tubes do not have to be opened at the time of reaction, the risk of carry over contamination gets considerably reduced. In recent years, some commercial automated real-time PCR systems have been available (Light Cycler \& TaqMan). In these systems, such as the Light Cycler TM and the Smart Cycler ${ }^{\circledR}$, these systems perform the real-time fluorescence monitoring by using fluorescent dyes such as SYBR-Green I, which binds non-specifically to double-stranded DNA generated during the PCR amplification. Others, such as the TaqMan, use florescent probes that bind specifically to amplification target sequences.

These techniques can be divided roughly into three categories, depending on the basis for discriminating the allelic variants:

\section{Enzymatic-Based Methods}

The first restriction enzyme based approach used extensively was RFLP analysis. It exploits the alterations in restriction enzyme sites, leading to the gain or loss of restriction events [6]. Since then a number of enzymatic approaches for mutation detection have been conceived, based on the dependence of a secondary structure on the primary DNA sequence. These methods utilize the activity of resolvase enzymes T4 endonuclease VII, and more recently, T7 endonuclease I to digest heteroduplex DNA formed by annealing wild type and mutant DNA [9]. Mutations are indicated by the size of the various fragments. A variation of the theme involves the use of chemical agents for the same purpose [10]. Another enzymatic approach for mutation detection is the oligonucleotide ligation assay [11]. This technique involves the hybridization of two oligonucleotides to complementary DNA stretches at sites of possible mutations. The oligonucleotide primers are designed such that the $3^{\prime \prime}$ end of the first primer is immediately adjacent to the $5^{\prime \prime}$ end of the second primer. Therefore, if the first primer matches completely with the target DNA, then the primers can be ligated by DNA ligase. On the other hand, if a mismatch occurs at the $3^{\prime \prime}$ end of the first primer, then no ligation products will be obtained.

\section{Electrophoretic-Based Techniques}

This category is distinguished by a number of different approaches intended for screening of known or unknown mutations, based on the different electrophoretic mobility of the mutant alleles, under denaturing or nondenaturing 
conditions. Using this technique, Single strand conformation polymorphism (SSCP) and heteroduplex (HDA) analyses [12], were among the first methods designed to spot molecular defects in genomic loci. In combination with capillary electrophoresis, SSCP and HDA analysis now provide an excellent, simple, and rapid mutation detection platform with low operation costs and, most fascinatingly, the potential of easily being automated, thus allowing for high-throughput analysis of patient's DNA. Another equally well employed technique for mutation detection is, Denaturing and Temperature Gradient Gel Electrophoresis (DGGE and TGGE, respectively). In this case, electrophoretic mobility differences between a wild type and mutant allele can be "visualized" in a gradient of denaturing agents, such as urea and formamide, or of increasing temperature. Lastly, an increasingly used mutation detection technique is the two-dimensional gene scanning, based on two-dimensional electrophoretic separation of amplified DNA fragments, according to their size and base pair sequence. The latter involves DGGE, following the size separation step.

\section{Solid Phase-Based Techniques/Hybridization or Blotting Techniques}

This set of techniques consists of the foundation for most of the present-day mutation detection technologies owing to their extra advantage of being effortlessly automated and hence are highly recommended for high throughput mutation detection or screening. In 1970s there was out break on Nucleic acid hybridization techniques that is based on the pairing of two complimentary nucleotide strands mainly due to involvement of hydrogen thus duplex or hybrid results. The hybrids may be resultant of DNA-DNA, RNA-RNA, or DNA-RNA, thus single stranded molecule may be DNA or RNA in which one nucleic acid strand (the probe) originates from an organism of known identity and the other strand (the target) originates from an unknown organism to be detected or identified.

Saiki et al. [13] developed a fast, accurate, and convenient method for the detection of known mutations reverse dot-blot, and implemented it for the detection of b-thalassemia mutations. The essence of this method is the utilization of oligonucleotides, bound to a membrane, as hybridization targets for amplified DNA. Some of this technique's advantages are that one membrane strip can be utilized to detect many different known mutations in a single individual (a one strip-one patient type of assay), the potential of automation, and the ease of interpretation of the results, using a classical avidin-biotin system. However, the disadvantage is that this technique cannot be used for the detection of unknown mutations. Continuous development has given rise to allele-specific hybridization of amplified DNA (PCR-ASO), on filters and newly extended on DNA oligonucleotide microarrays for high throughput mutation analysis [14]. Recently, Petralia et al. (2016) have reported a point of care real time PCR platform for the detection of pathogen species HBV [15]. The core of the platform is a hybrid microchip composed by a silicon part and a polycarbonate portion mounted on the plastic ring. The experiments were conducted at different annealing temperature and probe amounts and the results indicated an improvement of sensitivity of about $1 \mathrm{Ct}$.

\section{Microarrays}

A microarray is a battery of enhanced features of microscopic technique. This technique usually involves hybridization of DNA with target molecule, for quantitative (gene expression) or qualitative (diagnostic) analysis of large numbers of genes simultaneously or to genotype multiple regions of a genome. Each DNA spot contains approx. picomoles $\left(10^{-12} \mathrm{~mol}\right)$ of a specific DNA sequence, known as probes (or reporters). There has been a tremendous improvement in the microarray technology in terms of efficiency, discriminatory power, reproducibility, sensitivity and specificity due to advances in fabrication, robotics, and bioinformatics, these improvements have allowed the transition of microarrays from strictly research bench site to bed site in clinical diagnostic applications. Microarrays can be differentiated on the basis of characteristics such as the nature of the probe, the solid-surface support used, and the specific method used for probe addressing and/or target detection.

Further, advances appear in the form of In-situ-synthesized arrays, which are extremely-high-density microarrays that use oligonucleotide probes, for example Gene Chips (Affymetrix, Santa Clara, CA) are the most widely known. In-situ synthesized arrays are synthesized directly on the surface of the microarray made up of $1.2 \mathrm{~cm}^{2}$ quartz wafer unlike the printed oligonucleotide arrays described above because in situ-synthesized probes are typically short (20-25 bp), multiple probes per target are included to improve sensitivity, specificity, and statistical accuracy. Yet another type are the bead array, similar to the above mentioned printed and in situ-hybridized microarrays, Bead Arrays (Illumina, San Diego, CA) provide a patterned substrate for the high-density detection of target nucleic acids. However, instead of glass slides or silicon wafers as direct substrates, Bead Arrays rely on 3- $\mu \mathrm{m}$ silica beads that randomly self-assemble onto one of two available substrates: the Sentrix Array Matrix (SAM) or the Sentrix Bead Chip [15]. Unlike the other array the exclusive feature of Bead Arrays rely on passive transport for the hybridization of nucleic acids. One more type of array, 
electronic microarrays utilize active hybridization via electric fields to control nucleic acid transport. Microelectronic cartridges (NanoChip 400; Nanogen, San Diego, CA) use complementary metal oxide semiconductor technology for the electronic addressing of nucleic acids [16]. Each Nano Chip cartridge has 12 connectors that control 400 individual test sites. In contrast to the above mentioned arrays, which are 2-D based, Suspension bead arrays are essentially three-dimensional arrays based on the use of microscopic polystyrene spheres (microspheres or beads) as the solid support and flow cytometry for bead and target detection. Furthermore, they are distinct from the highdensity Illumina Bead Arrays, in which the beads are immobilized on fiber-optic strands or silicon slides. Most of the clinical diagnostic laboratories have not chosen expensive high technology infrastructure, as the number of tests expected to be performed, have not been large enough to justify the capital outlay. Therefore, simple screening tests such as SSCP and HDA were and still are the methods of choice for many clinical laboratories, as they allow for rapid and simultaneous detection of different sequence variations at a detection rate of close to $100 \%$.

\section{Sequencing}

Although PCR has significantly facilitated the expansion of molecular diagnostics, it nonetheless has a number of limitations. First of all, it is problematic for Taq Polymerase to amplify CG repeat-rich regions which sometimes leads to the classic alternative of Southern blot analysis. Also, Taq Polymerase is error-prone at a range of $10^{4}-10^{5}$ nucleotide, which is strongly influenced by the conditions of the amplification reaction, such as magnesium or deoxyribonucleotide concentration, $\mathrm{pH}$, temperature, and so on. Due to Polymerase errors there can be unspecific background, depending on the detection method, resulting in limiting the detection level. To overcome these technical problems, positive results should be confirmed by alternative methods or by using high fidelity thermo stable polymerases. Finally, it needs to be stressed that despite the wealth of mutation detection methodologies, DNA sequencing technology has immensely contributed to detection of unknown mutations. Until the late 1970s, determining the sequence of a nucleic acid containing even five or ten nucleotide was an extremely difficult and laborious task. After introduction of new technique of DNA sequencing, which includes several methods and technologies that are used for determining the order of the nucleotide bases-adenine, guanine, cytosine, and thymine-in a molecule of DNA, the knowledge of DNA sequences has become indispensable for basic biological research and in numerous applied fields such as diagnostic, biotechnology, microbiology etc. There has been significant acceleration in the field of biological research and discovery with the advent of DNA sequencing. Several microbial genomes have been sequenced using this technique. In 1977, two different methods for sequencing DNA were developed, that is, the chain termination method and the chemical degradation method. In 1976-1977, A. Maxam and W. Gilbert developed a DNA sequencing method based on chemical modification of DNA and subsequent cleavage at specific bases. This rapidly became more accepted, since purified DNA could be used directly, while the initial Sanger method required that each read start be cloned for production of single-stranded DNA. However, with the improvement of the Sanger method, Maxam-Gilbert sequencing has less popular due to its technical complexity, prohibiting its use in standard molecular biology kits, extensive use of hazardous chemicals, and difficulties with scale-up. Each of four reactions $(\mathrm{G}, \mathrm{A}+\mathrm{G}, \mathrm{C}$, and $\mathrm{C}+\mathrm{T})$. Thus a series of labeled fragments are generated, from the radio labeled end to the first "cut" site in each molecule. Size based separation of the fragments in the four reactions is done by parallel electrophoresis on a denaturating acrylamide gel. Visualization is done by exposure of gel to X-ray film for autoradiography, yielding a series of dark bands each corresponding to a radiolabeled DNA fragment, from which the sequence may be inferred. This method is sometimes called "chemical sequencing" method. The chain-terminator method or Frederick Sanger method became a popular method of DNA sequencing due to its greater efficiency and use of fewer toxic chemicals and lower amounts of radioactivity than the method of Maxam and Gilbert. The key principle of the Sanger method was the use of dideoxynucleotide triphosphates (ddNTPs) as DNA chain terminators.

\section{Molecular Diagnostics in the Post-genomic Era}

A new era of molecular biology dawned in February 2001, when the first draft sequence of the human genome was declared (International Human Genome Sequencing Consortium 2001) and was followed up with the genomic sequences of other organisms, with the new era came new opportunities and challenges. Post human genome draft publication, the major challenge, was to improve the existing mutation detection technologies to achieve robust cost effective, rapid, and high-throughput analysis of genomic variation. In the last decade, technology has improved rapidly and new mutation-detection techniques have become available, whereas old methodologies have evolved to fit into the increasing demand for automated and high throughput screening. Denaturating high performance liquid chromatography (DHPLC) used for detection of polymorphic changes of disease-causing mutations one of the new technologies that emerged. It detects the presence 
of a genetic variation by the differential retention of homoand heteroduplex DNA on reversed-phase chromatography under partial denaturation. DHPLC has proved to be one of the most powerful tools of mutation detection and is capable of detecting single-base substitutions, deletions, and insertions can be detected successfully by UV or fluorescence monitoring within 2-3 min in unpurified PCR products as large as 1.5-kilo bases. Another useful technique of mutation analysis is Pyro sequencing, which is a non-gel-based genotyping technology, and provides a very reliable method and an attractive alternative to DHPLC. Pyrosequencing detects de novo incorporation of nucleotides based on the specific template, causing release of a pyrophosphate, which is converted to ATP and followed by luciferase stimulation. The light produced, detected by a charge couple device camera, is translated to a pyrogram, from which the nucleotide sequence can be deducted [17].

There has been a steady increase in the number of samples being sent for molecular analysis. This is due to sensitive and robust techniques like real time PCR and high throughput techniques like microarray. Among the various molecular techniques discussed above, the use of the PCR in molecular diagnostics is considered the gold standard for detecting nucleic acids and it has become an essential tool in the research laboratory. There is a wider acceptance for Realtime PCR [17] due to its improved rapidity, sensitivity, and reproducibility. There is a real time detection of the PCR product during the exponential phase of the reaction, thereby combining amplification and detection in one single step. The reduced number of cycles, use of fluorogenic labels and sensitive methods of their detection has largely removed post-PCR detection procedures, making the technique sensitive. Currently, newborns can be screened for phenylketonuria and other treatable genetic diseases. In the future, we might see children at high risk for coronary artery disease getting characterized and treated to prevent changes in their vascular walls during early adulthood. In the near future, we could witness as a part of standard medical practice, the individual drug monitoring response profiles throughout life, using genetic testing for the identification of their individual DNA signature, Shortly, genetic testing will comprise a wide spectrum of different analyses with a host of consequences for individuals and their families, which is worth emphasizing when explaining molecular diagnostics to the public.

\section{Current Scenario of Molecular Diagnosis in Various Diseases}

Clinical laboratories have seen a boost in a number of molecular techniques finding utility in diagnosis and monitoring of disease conditions. Right from plasmid profiling, various methods for generating restriction fragment length polymorphisms, to polymerase chain reaction $(\mathrm{PCR})$ and micro-arrays have all made increasing inroads into clinical laboratories. Among the molecular techniques, the most popular one for characterization of etiologic agents of disease directly from clinical samples has been PCR based methods as it allows for rapid detection of unculturable or fastidious microorganisms directly from clinical samples. Over the past two decades, the relentless progress and application of molecular diagnostic techniques has opened new vistas in the diagnosis of not only microbial diseases but also in other diseases and disorders like neurodegenerative disorders, cancers and genetic diseases. The various classes of mRNA have like non coding (lnc and snc), micro RNAs and genetic variants of various diseases like cancer, Alzheimer, Parkinson etc. have been identified and characterized, which may be useful in management of these patients.

\section{Application of Various Molecular Techniques in Microbial Diseases}

\section{Role of Hybridization Technique in Microbial Disease}

At present it is used for DNA and RNA for microbial characterization and identification. With some modification in traditional probe hybridization, the fluorescent in situ hybridization (FISH) evolved, which is a highly valuable tool for the specific and rapid detection of pathogenic bacteria in clinical samples without cultivation [18]. As reported in patients with exacerbations due to $H$. influenzae, S. aureus, and P. aeruginosa and FISH is used for the rapid detection of microorganisms that cause acute pulmonary infections with $100 \%$ sensitivity. The phylogenetic identification of single cell microbes has been successfully done based upon their 16S rRNA sequences as some of these sequences are in all organisms. FISH probes complementary to specific sequence of 16s rRNA can detect malaria infection in blood samples. This assay is highly sensitive and can identify all five species of Plasmodium known to cause malaria in humans and its better than that of Geimsa stain [19].

FISH technique has allowed for the development of low cost molecular tests like the DNA probe methods that detect C. trachomatis or N. gonorrhea are examples of lowcost molecular tests. For hybridization assays such as the INNO-LiPA $^{\circledR}$ Rif.TB (Innogenetics) and GenoType ${ }^{\circledR}$ MTBDR (plus) (Hain Life Science GmbH) line-probe assays displays a pooled good sensitivity and a specificity of 0.99 for detecting rifampin resistance in isolates or directly from clinical specimens. Amplification of the detection signal after probe hybridization improves 
sensitivity to as low as 500 gene copies per micro liter and provides quantitative capabilities. This approach has been widely utilized for quantitative assays of viral load (hepatitis $\mathrm{B}$ virus $[\mathrm{HBV}]$ and hepatitis $\mathrm{C}$ virus $[\mathrm{HCV}]$. Further the development of dual colour FISH recently has allowed the detection of $\mathrm{M}$. tuberculosis and $\mathrm{M}$. avium from other pathogens in bacterial cultures with a high sensitivity and at a rapid pace of less than $2 \mathrm{~h}$ detection time [20].

FISH probes commercially available in market uses solution-phase hybridization and chemiluminescence for direct recognition of microbial agents in sample material like PACE2 products of Gen-Probe and the hybrid capture assay systems of Digene and Murex. These systems are flexible as they are adaptable to small or large numbers of specimen, are simple to handle and work, besides having a long shelf life. The PACE2 products now help in detection of both Neisseria gonorrhoeae and Chlamydia trachomatis in a single specimen (one specimen, two separate probes). The hybrid capture systems identify human papillomavirus (HPV) in cervical scrapings, herpes simplex virus (HSV) in vesicle material, and cytomegalovirus (CMV) in blood and other fluids. Although less sensitive than the target amplification based methods for detection of viruses, these methods do give the quantitative results which have proven fruitful for determining viral load and prognosis and for monitoring response to therapy [21]. Probe hybridization is useful for identifying slow growing organisms after isolation in culture using either liquid or solid media. Identification of mycobacteria and other slow-growing organisms such as the dimorphic fungi (Histoplasma capsulatum, Coccidioides immitis, and Blastomyces dermatitidis) has certainly been facilitated by commercially available probes. All commercial probes for recognizing organisms are produced by Gen-Probe and use acridinium ester-labeled probes directed at species-specific rRNA sequences. GenProbe products are available for the culture identification of Mycobacterium tuberculosis, M. avium-intracellulare complex, M. gordonae, M. kansasii, Cryptococcus neoformans, the dimorphic fungi, N. gonorrhoeae, Staphylococcus aureus, Streptococcus pneumoniae, Escherichia coli, Haemophilus influenzae, Enterococcus spp., S. agalactiae, and Listeria monocytogenes. The sensitivity and specificity of these probes are excellent, and they provide species identification within 4-6 h. The mycobacterial probes, on the other hand, are accepted as a common method for the identification of $M$. tuberculosis and related species [22]. Shah et al. 2017 have successfully utilized MN Genus-MTBC and MTBC-MAC FISH assays as effective diagnostic tools for detecting Mycobacteria from solid and liquid cultures and for their identification as MTBC, MAC or NTM other than MAC. he two FISH assays have a LOD of at least $5.1 \times 104 \mathrm{cfu}$ of bacilli per $\mathrm{ml}$ which can help minimize delays in diagnosis by being applicable relatively early after initiation of cultures [20].

\section{Role of Microarray Technique in Microbial Disease}

Nübel et al. [23] used the PCR amplification, in combination with an oligonucleotide microarray, to identify Bacillus anthracis based on the rRNA ITS region. Several studies reported the use of microarrays to identify pathogenic yeasts and molds by targeting the ITS regions in fungal rRNA genes [24]. Recently, a DNA microarray was established to detect and identify 14 commonly encountered fungal pathogens in clinical specimens collected from neutropenic patients [25]. A microarray technique for the detection and identification of enteropathogenic bacteria at the species and subspecies levels was developed, covering pathogenic E. coli, Vibrio cholerae, Vibrio parahaemolyticus, Salmonella enterica, Campylobacter jejuni, Shigella spp., Yersinia enterocolitica, and Listeria monocytogenes [26]. Recently a study has developed a new oligonucleotide microarray comprising 16 identical subarrays for simultaneous rapid detection of avian viruses: avian influenza virus (AIV), Newcastle disease virus (NDV), infection bronchitis virus (IBV), and infectious bursal disease virus (IBDV) in single- and mixed-virus infections. Diagnostic effectiveness of the developed DNA microarray has been $99.18 \%$ and therefore can prove highly effective in mass survey for specific detection of AIV, NDV, IBV and IBDV circulating in the region in the course of epidemiological surveillance [27].

\section{Role of Polymerase Chain Reactions (Multiplex, Nested/Semi-nested, Broad Range, Reverse Transcription and Real Time) in Microbial Disease}

PCR is a very robust technique for the detection of minute quantities of specific microbial DNA sequences owing to its ability to amplify minute amounts (less than 3 copies) of specific microbial DNA sequences in a background mixture of host DNA. Many micro-organisms, have been identified using this technique for example Mycobacterium tuberculosis, pneumococci, meningococci and Burkholderia cenocepacia. Over 100 viruses are known to cause acute viral encephalitis in humans. There is a battery of infective states of CNS which can be accounted for by viral infections like those involving the spinal cord (myelitis), the brain stem (e.g., rhombencephalitis), the cerebellum (cerebellitis), or the cerebrum (encephalitis) and almost all acute viral infections of the CNS produce some degree of meningeal as well as parenchymal inflammation. Rarely, such as West Nile virus (WNV) meningoencephalitis or cytomegalovirus (CMV) radiculomyelitis, polymorphonuclear cells rather than lymphocytes may be the predominant cell type, and thus provide some diagnostic guidelines. Even with such a diverse symptoms routine CSF studies only rarely lead to identification of a specific etiologic 
agent. The entire picture of diagnosis of viral infections of CNS has changed for good now a days due to the discovery of new molecular diagnostic technologies, such as the PCR to amplify viral nucleic acid from CSF [28, 29]. The realtime multiplex PCR assay designed by researchers is extremely rapid and permits the confirmation of bacterial isolates as Brucella spp., B. abortus, or B. melitensis within 2-3 h. Further this technique has assisted in the identification of infrequently isolated Brucella species and the recognition of atypical Brucella strains by utilizing genus specific primers-probe sets. This is advantageous since the conventional methods for Brucella isolation and characterization may take days to weeks to perform and often requiring the preparation of heavy suspensions of these highly infectious pathogens [30]. Since viral disease severity and viral load are linked, use of real-time PCR quantitation has proven beneficial when studying the role of viral reactivation or persistence in the progression of disease [31]. Nonetheless, the general diagnosis of invasive diseases caused by Aspergillus fumigatus and Aspergillus flavus has been made easier by real-time PCR assays [31]. The diagnosis of efflux-mediated resistance in Pseudomonas aeruginosa has been performed by using molecular diagnostic approach. Real time PCR has helped in the detection of mexA and mexX and reverse transcription pCR for mex $\mathrm{C}$ and mex $\mathrm{E}$, thus helping in the analysis of multidrug resistance in $P$. aeruginosa [28].

Recently Jiang et al. developed an assay combining multiplex PCR and Luminex technology (MPLT) for the detection of nine important respiratory bacterial pathogens, which frequently cause LRTIs including S. pneumoniae, Moraxella catarrhalis, S. aureus, Streptococcus pyogenes, Haemophilus influenzae, Mycoplasma pneumoniae, Legionella spp., P. aeruginosa, and Klebsiella pneumonia assay demonstrated a high diagnostic accuracy for $S$. pneumoniae (sensitivity, 87.5\% and specificity, 100\%). Furthermore, sensitivity and specificity for the other eight pathogens all attained 100\% diagnostic accuracy. Indeed, this assay may be a promising supplement to conventional methods used to diagnose LRTIs [32].

\section{HIV Qualitative Nucleic Acid Assays}

The qualitative detection of HIV nucleic acids finds application in three main areas: the identification of acute infection, assurance of blood safety, and in early infant diagnosis. Shortcomings of western blot analysis in confirmation of HIV infection have been overcome by an amended testing algorithm employing qualitative nucleic acid testing [33]. The APTIMA HIV-1 RNA Qualitative
Assay and the Procleix HIV- 1/HCV assay (Gen-Probe, San Diego, CA, USA) are both Food and Drug Administration (FDA)-approved for blood-donor screening to exclude blood from donors with acute HIV infection [34]. Transcription-mediated amplification technology is used in these two assays [35]. Infants born to mothers infected with HIV-1 have maternal antibodies directed against HIV up to 18 months of age and prevents the use of antibody-based assays for the early diagnosis of HIV infection. Such infected infants have a high morbidity and mortality in the first 2 years of life; thus, an early diagnosis is important to establish the infection status of the exposed infant in order to employ appropriate ART sufficiently early. Qualitative nucleic acid assays for the detection of HIV pro-viral DNA, viral RNA and total nucleic acid [36], have become the methods of choice for diagnosis in infants born to HIV-1infected mothers. Cobas AmpliPrep/COBAS ${ }^{\circledR}$ TaqMan ${ }^{\circledR}$ HIV-1 Qualitative Test is one such test that uses $70 \mu \mathrm{l}$ of whole blood or dry blood spot, and is directed against gag and LTR regions of HIV-1 genome.

H CD-4 T cells numbers and HIV RNA viral load are two routinely used laboratory markers in chronically infected patients and serve as guide ART initiation, monitor treatment effectiveness, determine clinical progression [37], and determine treatment regimens. An HIV RNA level below the detection limit is indicative of excellent compliance by patients and ART efficacy [37]. HIV-1 viral load determination is typically performed with HIV RNA amplification by reverse transcription-polymerase chain reaction (RT-PCR), nucleic acid sequence-based amplification (NASBA) or branched chain DNA tests. New microarray techniques including those from Affymetrix (Santa Clara, CA, USA), have currently allowed host transcriptome analyses in individuals infected with HIV-1 [38], and 34 studies involving HIV-1 and microarrays from 2000 to 2006 yielded important data on HIV-1-mediated effects on gene expression and provided new insights into the intricate interactions occurring during infection [39]. The host transcriptome profiles may prove to extremely important for the evaluation of disease progression and prognosis and RNA-Seq approach using deep-sequencing technologies for transcriptome profiling will further add to the precision of transcriptome analyses [38]. Gen-Probe's (APTIMA $^{\circledR}$ ) HIV-1 RNA qualitative assay, is the only molecular assay that is FDA approved for diagnosis of acute infections and as a confirmatory test for diagnosing HIV-1 in samples that test reactive for HIV-1 antibodies. Other commercially available molecular assays were developed as quantitative viral load assays for therapeutic monitoring, and are currently only available in expensive, high-throughput formats. 


\section{Role of Sequencing in Microbial Disease}

Sequencing of broad range of PCR products has facilitated the identification of almost any bacterial species by comparing the resulting sequences with known sequences in GenBank or other databases, the identification of the unknown bacteria is possible. Sequencing of 16S rRNA has become an important tool, which has been used more and more in microbial detection and identification algorithms, especially for unusual, non-culturable, fastidious and slow growing pathogens, or after antibiotics that have been administered to the patient. Thus this technique is helping in combat infectious diseases, where a consistent detection of bacteria in specimens would prove critical in diagnosis and future therapy. Under these circumstances, PCR is the most reliable assay for detection of microbes in clinical specimens. The major challenge in the rapid detection, identification and characterization of microbial pathogens lies in the accurate recognition of a traits, species, sub species and genus, or combination of traits, that is unique to a specific microbial strain [40]. Increasingly, DNA based assays are replacing the conventional serotyping based methods. Rather DNA based assays detect known genomic signatures generally on 16s rRNA-based almost that is conserved by nature And offer rapid and reliable identification of microbial pathogens in most precise manner [41]. New DNA sequencing platforms are already enabling novel approaches to explore and characterize microbial genomes, while at the same time profoundly altering our understanding of the natural genetic diversity exist in microbial populations. Table 2 representing various established techniques currently used in screening of microbial infections.

\section{Genetic Diseases, Disorders and Molecular Diagnosis}

The worth of the interaction between basic science and clinical practice has very close association but it has become even more apparent in the past sixty years with the notable rate of development in the field of molecular genetics.

\section{Fragile X Syndrome}

Tri-nucleotide repeat DNA sequences positioned within the transcribed region of a gene can expand, by a process of vibrant mutation, likely due to a mechanism of 'strand slippage' during DNA replication and ultimately compromise the function of the gene dynamic mutations of CGG triplets give rise to folate-sensitive fragile sites of human chromosomes. Primarily these fragile sites to be cloned and characterized which is accountable for the single most common form of inherited mental retardation, the Fragile $\mathrm{X}$ Syndrome. This syndrome, clinically well-defined by the presence of mental retardation of variable severity, modest facial dysmorphism and macroorchidism in adult males, has been documented for years as an X-linked Mendelian disorder offering abnormal and confusing features of inheritance, penetrance, cytogenetic expression and clinical variability. The mainstream of males who carry the Fragile X Mutation (FRAXA) are exaggerated by mental retardation and show a cytogenetically inducible fragile site, but $20 \%$ of obligate male carrier, the so called 'normal transmitting males', are both clinically and cytogenetically negative. Overall, characteristic can be defined by the nature of the FRAXA dynamic mutation and the inactivation of the FMR1 (Fragile X Mental Retardation 1) gene, coding for the RNA-binding protein (FMRP), typically expressed in human brain and testis. The 59 untranslated region of the FMR1 gene harbors a series of CGG triplet repeats, highly polymorphic in normal individuals; the total of these repeated units varies from 4 to about 54 . A FRAXA mutation is demarcated as a 'premutation' when the repeats increase beyond the upper-normal limits to a size of about 200 triplets, characteristic of carrier females and normal transmitting males in whom, despite the structural modification, the gene is expressed and the protein is functional [42]. The altered allele transmitted by a premutated mother to her offspring scarcely ever shows small decreases of the repeats; more commonly, with a risk that is higher for larger premutations, it undertakes a process of expansion that can reach a size increase of more than 2000 repeats and is referred to as the 'full mutation' [43].

\section{Molecular Diagnosis of FRAXA Mutations}

Direct molecular diagnosis of Fragile $\mathrm{X}$ Syndrome is marked at the discovery and measurement of the abnormal expansion of the CGG repeats region and at the characterization of the state of methylation of the FMR1 promoter, a reflection of the residual function of the gene. There is a rational international consensus on the detail that DNA-based testing for the FRAXA mutation should be skilled through the combined use of two techniques: PCR amplification and Southern blot/Hybridization.

This is the tactic commonly selected to adopt for the molecular analysis of FRAXA mutations that is regularly done by diagnostic service as part of the different diagnosis of mental retardation of unknown cause. The other way is screened by Southern blotting of genomic DNA digested with a combination of restriction enzymes that includes 
Table 2 Molecular techniques utilized for characterization of various microbes

\begin{tabular}{|c|c|c|}
\hline Organism & Techniques & Infections \\
\hline \multirow[t]{2}{*}{ CMV } & Qualitative PCR & CNs Infection \\
\hline & Real-time PCR & Congenital Infection \\
\hline \multirow[t]{3}{*}{ Influenza and para influenza viruses } & RT-PCR & Flu \\
\hline & Real-time PCR & Bronchiolitis \\
\hline & Multiples PCR & Croup \\
\hline \multirow[t]{2}{*}{ HIV } & Real-time quantitative PCR & HIV/AIDS \\
\hline & (Viral load Detection) & \\
\hline \multirow[t]{2}{*}{ Hepatitis } & Real-time PCR & Hepatitis (chronic) \\
\hline & Hybridization & \\
\hline Middle-East Respiratory Syndrome & RT-PCR & MERS-CoV pneumonia \\
\hline Coronavirus (MERS-CoV) & Real-time PCR & Vaginitis \\
\hline Group-B Streptococcus (GBS) & 16s rDNA PCR & Meningitis \\
\hline Neisseria Meningitides & 16s rDNA PCR & Osteomyelitis \\
\hline \multicolumn{3}{|l|}{ Helicobacter species } \\
\hline Plasmodium falciparum & Nested PCR & Malaria \\
\hline Methicillin-resistant Staphylococcus aureus (MRSA) & Multiples PCR & Health care associated \\
\hline \multirow[t]{3}{*}{ Multi-drug resistant $M$. tuberculosis } & Real-time & Infections \\
\hline & PCR (Gene Xpert) & Tuberculosis \\
\hline & & MDR-TB \\
\hline Brucella spp., B. abortus, or melitensis & Real-time PCR & Brucellosis \\
\hline \multirow[t]{3}{*}{ Stenotrophomonas maltophila } & 23S rRNA based & Cystic fibrosis \\
\hline & Specific oligonucleotide probes & \\
\hline & Real-time PCR & \\
\hline
\end{tabular}

methylation-sensitive rare cutters, followed by hybridization to a suitable labeled probe. This is a more time-consuming and labor-intensive procedure, it may be not as accurate in discriminating small premutations from large normal alleles, but it can be used as the only test since it ensures a reliable and complete diagnosis [44].

\section{Familial Cancer Syndromes: The Von Hippel- Lindau Disease}

Mutations of a gene mapped to the distal end of the short arm of chromosome 3 (3p25-26), have now been found to be accountable for the von Hippel-Lindau disease, a highly penetrant, dominantly inherited syndrome showed by susceptibility to a variety of benign and malignant tumors. Pathologic conclusions are retinal and central nervous system hemangioblastomas, pheochromocytomas, and renal and pancreatic cancer. In von Hippel-Lindau disease both sexes are equally involved, there is a penetrance of about $90 \%$ at the age of 65 with a mean age at diagnosis of 26 years. TheVHL gene is $1810 \mathrm{bp}$ in length, with an open reading frame (ORF) of $852 \mathrm{bp}$ and two in-frame starting codons; it is composed of three exons, with exon 2 alternatively spliced. The alternative transcripts are ubiquitously expressed in a tissue-specific and developmentally selective manner [45]. The study of the normal function of this tumor suppressor gene promises a wide gain in our knowledge of the mechanisms of gene transcription: VHL acts as a competitor of Elongin (SIII), one of the transcription elongation factors, and can modify vascular endothelial growth factor and neoangiogenesis, upon which tumor growth is dependent. The practical approach is precise for the finding of medium small-size mutations, the type of alteration commonly found in the VHL pheochromocytoma phenotype [46]. Detection is done with the procedure of PCR amplification of partially overlapping genomic DNA fragments covering the entire coding sequence of the VHL gene and including exon-flanking intronic regions. The amplification products are subjected to polyacrilamide gel electrophoresis (PAGE), for detection of deletion/insertion mutations that may change the molecular weight of the product, and to Single Strand Conformation Polymorphism (SSCP) analysis. This method, designed to specifically identify single base substitutions, is the most widely used mutation scanning 
technique; it is based on the tendency of single stranded DNA molecules to assume a three-dimensional conformation which is dependent on the primary sequence, is very specific and can be simply detected on a native polyacrylamide gel. DNA fragments that show size alterations on PAGE analysis or aberrant SSCP bands are subsequently subjected to direct automated sequencing to confirm and characterize the mutation. This strategy has allowed to identify different mutations, in unrelated VHL patients, and to detect case of somatic mosaicism in an asymptomatic subject [47].

\section{Cystic Fibrosis (CF)}

Cystic fibrosis (CF) is the most common autosomal recessive inherited disease in Caucasians and affects approximately 1 in 2500 individuals. It is a multifaceted disorder that influence Pulmonary, Pancreatic, Gastro-intestinal, and Reproductive organ system. The pathological processes influencing these organ systems happen due to mutations in the CFTR gene which encodes the cystic fibrosis transmembrane conductance regulator, a membrane chloride channel present in the apical membrane of secretory epithelia. The CFTR protein is a cyclic-AMP dependent channel, activation of protein kinase A occurs when there is increase in levels of c-AMP inside a secretory epithelial cell ultimately it binds to the phosphorylation site on the (regulatory) R-domain of the CFTR protein thus opening the channel. The CFTR chloride channel essentially works as an electrostatic attractant by directing intracellular and extracellular anions toward positively charged transmembrane domains inside the channel. The CFTR protein includes 12 transmembrane (TM) domains. Two of these (TM1 and TM6) attract and bind chloride (and/or bicarbonate) ions. After binding chloride ions to these sites in the pore, the mutual repulsion hastens expulsion of the ions from the cell [48].

When CFTR is activated in general, chloride ions are secreted out of the cell. But, additionally with chloride ion secretion, the epithelial sodium channel $(\mathrm{ENaC})$ is also inhibited by CFTR (Konig et al. 2001), and less sodium is absorbed into the cell, maintaining a higher combined ionic gradient to allow water to depart the cell by osmosis providing fluid for epithelial tissue secretions. In cystic fibrosis these mucus secretions become hyperviscous that accounts for the main features of cystic fibrosis. There are more than 1950 individual CFTR mutations in recent times reported to cause CF (http://www.genet.sickkids.on.ca/cftr/app and http://www.hgmd.cf.ac.uk/ac/index.php). These are inactivating (loss of function) mutations and include deletions, insertions, splice site mutations, nonsense mutations as well as more than 650 missense mutations. The severity and appearance of the disease may depend on the type of mutation [49].

\section{Testing of Cystic Fibrosis}

Preliminary investigation of a sample is commonly done by means of a commercially available kit as there is no gold standard for routine testing; commercially available kit allows analysis of approximately 30 sequences variants, which are accountable for more than $90 \%$ of CF disease causing mutations. The mutations tested should be capable of identifying at least $80 \%$ of mutations e.g., at least p.Phe508del (F508del), p.Gly551Asp, (G551D), p.Gly542X (G542X) and c. $489+1 \mathrm{G}>\mathrm{T}(621+1 \mathrm{G}$ $>\mathrm{T}$ ). Current methods used in CFTR testing can be categorized into two groups: targeting at known established mutations, and scanning methods. These now include exploration of large unknown CFTR rearrangements, including large deletions, insertions and duplications, by semi-quantitative PCR experiments, i.e. Multiplex Ligation-dependant Probe Amplification CFTR mutations may be missed by scanning techniques, especially when homozygous, and even direct sequencing cannot identify $100 \%$ of mutations [50]. Undetected CFTR mutations may penetrate deep within introns or regulatory regions which are not generally analyzed. For example $3849+$ $10 \mathrm{kbC}>\mathrm{T}(\mathrm{c} .3718-2477 \mathrm{C}>\mathrm{T})$ and $1811+1.6 \mathrm{kbA}>\mathrm{G}$ $(c .1679+1.6 \mathrm{kbA}>\mathrm{G})$, the detection of which require meticulous methodologies. Attention should also be pinpointed on heterogeneity, as it has been stated in patients with the classical form of $\mathrm{CF}$, including a positive sweat test, but this possibly concerns less than $1 \%$ of cases. Additionally mutations in the SCNN1 genes, encoding sodium channel $(\mathrm{ENaC})$ subunits have been revealed in non-classic CF cases where no CFTR mutations could be recognized by extensive mutation scanning [51].

\section{Eye Diseases and Molecular Diagnostics}

Present progress in molecular diagnosis has unknotted several monogenetic and multi-factorial relationships in eye diseases. In this segment we will focus on common genetic diseases and disorders that have known causative genes and available measures for prevention or treatment.

\section{Glaucoma}

Glaucoma is well documented for its heterogeneity and presently affecting more than $2 \%$ population globally over age 40 years. At least 15 genetic loci have been mapped for 
POAG and 2 loci for PCG, of which only GLC1A (myocilin, MYOC), GLC1E (optineurin, OPTN) GLC1G (WD repeat domain 36, WDR36, and GLC3A (cytochrome P4501B1, CYP1B1) have been described. Mutations in MYOC accountable for about $2-4 \%$ of POAG cases in European and American studies [52]. In Chinese populations prevalence of MYOC mutations to be $1.1-1.8 \%$ and OPTN mutations in $16.7 \%$ POAG patients [53]. Mutations in CYP1B1 were shown in $48 \%$ of French PCG patients, but only $20 \%$ of Japanese patients. In addition, CYP1B1 mutations were also identified in early-onset POAG, whereas MYOC mutations were linked with PCG. These studies suggested that CYP1B1 may act as a modifier of MYOC expression and that these two genes may interact through a common pathway [54].

\section{Age-Related Macular Degeneration (AMD)}

AMD is revealed by progressive demolition of the macula, leading to central vision loss. AMD approximately affects $1.5 \%$ of the general population in Western Europe. Stargardt macular dystrophy (STGD) is the most common hereditary form of macular degeneration. STGD is an autosomal recessive or less often dominant disorder of the retina and is commonly related with early-onset macular degeneration. Three contributing genes have been linked with AMD, complement factor $\mathrm{H}(\mathrm{CFH})$, ATP-binding cassette transporter (ABCA4), and apolipoprotein E (APOE). CFH informed to be a main gene for AMD [55]. One mutation in $\mathrm{CFH}, \mathrm{Y} 402 \mathrm{H}$, was found to be related for up to $50 \%$ of the attributable risk of AMD. The APOE allele $\varepsilon 2$ showed an increased risk for AMD while $\varepsilon 4$ conferred a protective role against AMD and ABCA4 mutation, T1428 M, was found in $8 \%$ of Japanese STGD patients [56].

\section{Retinitis Pigmentosa (RP)}

$\mathrm{RP}$ is a heterogeneous group of retinal degenerations often affecting the rod photoreceptors. RP causes night blindness, loss of peripheral vision, and eventually to a loss of central vision. The prevalence of RP is estimated to be about 1 in 3500 worldwide. (Rivolta et al. 2002) Currently 40 genetic loci have been associated with nonsyndromic RP, from which 32 genes have been recognize. Rhodopsin (RHO) mutations identified for more than $25 \%$ of adRP cases. Mutations in retinitis pigmentosa 1 (RP1) account for $6-8 \%$ of adRP cases and Retinitis pigmentosa GTPase regulator (RPGR) is a most important gene for XLRP [57].

\section{Retinoblastoma (RB)}

Retinoblastoma (RB) is the most predominant intraocular malignancy in children. It can be familial or sporadic, with an incidence of 1 in 15,000-20,000 live births in nearly all populations out of which about $50 \%$ of RB cases are heritable. Generally familial, bilateral, or unilateral multifocal $\mathrm{RB}$ is observed as carriers of a RB1 germ-line mutation. $\mathrm{RB}$ is transmitted in an autosomal dominant manner with 80-90\% penetrance. Secondary genetic and epigenetic changes in another gene(s) are necessary to precipitate tumor development [58].

The prevalence rate of germ-line mutation in sporadic $\mathrm{RB}$ in Chinese population is $19 \%(8 / 42)$, with $11 \%(3 / 28)$ among unilateral cases. The direct genetic testing can be achieved by sequencer, after exploring nucleotide sequence. Alternative approach for mutation analysis is by single strand conformational polymorphism (SSCP) or by confirmation-sensitive gel electrophoresis (CSGE), or by denaturing high-performance liquid chromatography (DHPLC). Other technical procedures can also be utilized to cover the whole spectrum of gene mutations, such as fluorescent in situ hybridization (FISH) or methylationspecific polymerase chain reaction (PCR). Presently Taqman probe based real time PCR is also utilized in exploring nucleotide sequence at particular locus. Pre-natal diagnosis is commonly restricted to untreatable and severe congenital eye disorders such as RB. For individuals with familial or bilateral RB, the RB1 genetic testing should be first performed on both peripheral blood and tumor DNA. The 27 known RB1 coding exons, splice boundaries, and the promoter can be amplified by PCR followed by direct sequencing [59].

\section{Molecular Diagnosis in Neurological Disorders and Diseases}

\section{Transmissible Spongiform Encephalopathies (TSEs)}

TSEs or prion diseases are critical disorders of the central nervous system initiated by unconventional infectious agents, prions, which do not seemingly contain any nucleic acid nor induce any specific immunological reaction in the host. Lack of nucleic acid makes unsuitability to use PCR or real time technique in this type of disorder. Various common transmissible spongiform encephalopathy are, (1) CJD (Creutzfeldt-Jakob disease), (2) GSS (GerstmannSträussler-Scheinker syndrome), (3) FFI (Fatal familial insomnia), (4) vCJD (variant Creutzfeldt-Jakob disease), (7) Scrapie, (6) CWD (Chronic wasting disease) and (7) BSE (Bovine spongiform encephalopathy) [60]. 
The main pathogenetic event in TSEs is the conformational change of a host protein, cellular $\operatorname{PrP}(\mathrm{PrPc})$, encoded by the prion gene PRNP, into a pathological isoform. This conformer, called PrPSc (after its first identification in experimentally scrapie-infected rodents) aggregates into amyloid fibrils and accumulates into neural and, often, lymphoreticular cells [61]. Although blood taken from vCJD patients and inoculated into susceptible mice does not always cause disease, it is still possible that low level of infectivity and, as a consequence, $\operatorname{PrP}^{\mathrm{Sc}}$ might be present in blood. Further efficiency and species barrier may upset its manifestations. Numerous Animal studies have shown that the pathogenesis of TSE as after experimental inoculation of rodents/Mice with TSE agents, $\operatorname{PrP}^{\mathrm{Sc}}$ is characteristically noticeable in the CNS weeks before the expression of disease and its level augments until the animal dies. As the rise of $\mathrm{PrP}^{\mathrm{Sc}}$ corresponds to that of infectivity, $\operatorname{PrP}^{\mathrm{Sc}}$ is commonly used as a surrogate marker for assessing the amount of infectivity in biological samples. The ratio of infectivity and $\operatorname{PrP}^{\mathrm{Sc}}$ is relatively constant in the hamster brain experimentally infected with the $263 \mathrm{~K}$ strain of scrapie at a mean value of $\sim 105-106$ protein molecules for one lethal dose 50 (LD50) [62]. But recently few techniques at pre-clinical levels have sufficient potency to be proved as good biomarkers as they can detect very low levels of these proteins like chemicophysical precipitation based protocols, affinity chromatography or affinity precipitation techniques. The amended isolation method for $\mathrm{PrP}^{\mathrm{Sc}}$ with sodium phosphotungstate [63], and novel molecules plasminogen, and protocadherin-2 binding with high affinity to $\mathrm{PrP}^{\mathrm{Sc}}$, might enhance new expectations for preclinical diagnosis of TSEs. Among the immunological methods of PrPSc screening, western blotting is mainly characterized and widely validated method. It offers the advantage of recognizing different forms of PrPSc through the analysis of the molecular mass and the relative abundance of di-, mono- and non-glycosylated bands. These parameters characterize the so-called PrP glycotype, a kind of 'PrP signature', which varies among different forms of TSEs. PrPSc glycotyping has been projected for differentiating various forms of TSEs (e.g., scrapie from BSE, sporadic from variant CJD and for improving the classification of human TSEs. In sporadic CJD, for example, the combination of the two most frequent PrPSc glycotypes (I and II) with the three possible genotypes of PrP at the polymorphic codon 129 (methionine homozygous, valine homozygous, or heterozygous) enables the sub classification of this form into six distinct groups, each of which presents distinct clinical and pathological features [64]. But this technique is time consuming and only few samples can be assessed at a time so ELISA can overcome these problems. Further development and up gradation in immune assay in the form of Dissociation-enhanced lanthanide fluorescence immunoassay/conformation-dependent immunoassay (DELFIA/CDI) is the latest-generation immunoassay with an ELISA format, where the detection system is sensitive time-resolved lanthanide fluorescence instead of chemiluminescence. It can measure picograms (10-12 g) of PrPSc per $\mathrm{ml}$ and thus represents one of the most sensitive technique for the detection of PrPSc [65]. Further one more technique MUFS (Multi-Spectral Ultraviolet Fluorescence Spectroscopy) characterizes proteins by their specific fluorescent pattern of emission when they are excited by ultraviolet radiation and bypasses the need for pre-treatment steps to eliminate PrPc or for antibody binding. It has the potential to discriminate cellular from pathological prion protein, and various forms of PrPSc from different strains. Moreover most sensitive and specific technique which uses fluorescent antibody with confocal microscopy in FCS (Fluorescence Correlation Spectroscopy) which recognizes single fluorescent molecules in solution as they pass between the exciting laser beam and the objective of a confocal microscope, equipped with a single-photon counter. It is performed quickly and requires only small amounts of samples. The assay solution is mixed with anti-PrP antibodies tagged with fluorophores that bind strongly to PrPSc aggregates, which become highly fluorescent and easily visible against the background of monomeric PrPc. This technique is $\sim 20$-fold more sensitive than western blot and was able to detect, for the first time, PrPSc in the CSF of $\sim 20 \%$ of CJD patients.

Further 14-3-3 proteins were also detected in the CSF of patients with genetic CJD carrying the codon 200 or the codon 210 mutation of the PRNP gene, in $\sim 50 \%$ of CSF samples taken from patients with vCJD. Further proteins released in the CSF after cerebral damage, such as tau, neuron-specific enolase (NSE), and S-100, are also increased in CJD patients, although their specificity, sensitivity and predictive values are always inferior, or at most equal, to those of 14-3-3 proteins. Genetic susceptibility to the disease is also seen in sporadic and iatrogenic CJD where $\sim 70 \%$ of affected individuals are homozygous for methionine at the polymorphic 129 site of PrP (The EUROCJD Group 2001) in vCJD, $100 \%$ of patients are methionine homozygous [66]. This susceptibility, however, cannot be used to predict who will develop the disease since $\sim 40 \%$ of the Caucasian population is methionine homozygous. (The EUROCJD Group 2001) The finding of a PrP-like gene (PRNDgene) located downstream from the PrP gene in mammalian species has provided hope that PRND and its encoded protein (Doppel, Dpl) contributes to the pathogenesis of TSEs, and be of help in the recognition of at-risk individuals. 


\section{Alzheimer Disease (AD) and Molecular Diagnostics}

Alzheimer is an aging-related neurodegenerative disorder demonstrated by irreversible loss of higher cognitive functions. The pathological hallmarks of $\mathrm{AD}$ include deposition of extracellular amyloid plaques, cerebrovascular amyloidosis and intracellular (Neurofibrillary tangles) NFTs. NFTs are made by hyper-phosphorylation of the microtubule-associated protein tau (MAPT), while proteolytic processing of the Amyloid beta Precursor Protein (APP) generates the neurotoxic Ab peptide, which has been involved in the formation of neuritic amyloid plaques. Recently Salvadores et al. defined a very sensitive method for biochemical diagnosis of $\mathrm{AD}$ based on specific detection of misfolded $A \beta$ oligomers. They were able to distinguish $\mathrm{AD}$ patients from control individuals influenced by a variety of other neurodegenerative disorders or no degenerative neurological diseases with overall sensitivity of $90 \%$ and specificity of $92 \%$. The protein misfolding cyclic amplification assay (Ab-PMCA), utilizes the functional property of $\mathrm{Ab}$ oligomers to seed the polymerization of monomeric Ab. Ab-PMCA allowed detection of as little as $3 \mathrm{fmol}$ of Ab oligomers. These findings provide the proof-of-principle basis for developing a highly sensitive and specific biochemical test for AD diagnosis [67].

Recently a study has shown reduced expression of novel gene P9TLDR, potentially a microtubule-associated protein involved in neuronal migration, from an intracerebral brain-site-specific ( $\mathrm{AD}$ temporal lobe vs. $\mathrm{AD}$ occipital lobe) polymerase chain reaction (PCR)-select cDNA suppression subtractive hybridization (PCR-cDNA$\mathrm{SSH}$ ) expression analysis. Additionally, this study also validated by in vitro AD-related cell model, amyloid-b peptide $(\mathrm{Ab})$-treated neurons which reduced P9TLDR expression correlated with increased tau protein phosphorylation [68].

\section{Late-Onset Alzheimer's Disease (LOAD)}

Recently Zhang et al. have discovered molecular systems linked with late-onset Alzheimer's disease (LOAD), by constructing gene-regulatory networks in 1647 post-mortem brain tissues from LOAD patients and nondemented subjects, they showed that LOAD reconfigures specific portions of the molecular interaction structure. Thus emphasised an immune- and microglia-specific module that is dominated by genes involved in phagocytosis, contains TYROBP as a key regulator, and is up regulated in LOAD. Mouse microglia cells over expressing intact or truncated TYROBP revealed expression changes that significantly overlapped the human brain TYROBP network [68].

\section{Molecular Diagnosis of Genetically Transmitted Cardiovascular Diseases}

Advances in molecular biology have improved our knowledge of the primary defects and basic mechanisms accountable for the pathogenesis of numerous diseases including cardio-vascular disease conditions and their phenotypic expression, and in the process, new approaches on cardiac diagnosis have been formulated.

\section{Hypertrophic Cardiomyopathy (HCM)}

HCM is a main and normally familial cardiac disease characterized by complex pathophysiology and unlimited heterogeneity in its morphological, functional, and clinical course. This wide diversity is pin-pointed by the fact that HCM may be seen in all phases of life, from the new-born to the elderly. The clinical course is extremely variable, with few patients remaining asymptomatic throughout life and others developing severe symptoms of heart failure, few die prematurely, either suddenly (often in the absence of prior symptoms) or owing to progressive heart failure. It has been marked, even from the preliminary descriptions of the disease, that HCM is commonly inherited as a Mendelian autosomal dominant trait [69]. HCM can be caused by a mutation in any 1 of 5 genes that encode proteins of the cardiac sarcomere: b-myosin heavy chain (on chromosome 14), cardiac troponin $\mathrm{T}$ (chromosome 1troponin I (chromosome 19), a-tropomyosin (chromosome 15), and cardiac myosin-binding protein $\mathrm{C}$ (chromosome 11). Moreover, mutations in 2 genes encoding crucial and regulatory myosin light chains have been reported in what may be an extremely rare form of HCM. This genetic diversity is further compounded by intragenic heterogeneity, with a total of more than 100 individual diseasecausing mutations identified for these genes. Available data support that mutations in the b-myosin heavy chain gene (myosin is the primary contractile protein in thick filaments of myofibrils) may responsible for as much as 35\% of familial HCM. All the known genetic myosin defects have proved to be missense mutations [70]. Cardiac troponin $\mathrm{T}$ mutations [71], responsible for an estimated $10-20 \%$ of familial HCM. Troponin $\mathrm{T}$ binds the troponin complex to tropomyosin and plays a major role in calcium regulation of cardiac contraction and relaxation.

\section{Long-QT Syndrome (LQTS)}

The long-QT syndrome (LQTS; Romano-Ward) is a rare familial disease transmitted as an autosomal dominant trait, causing a predisposition to syncope and sudden cardiac 
death (often related to emotional or physical stress, vigorous activity, or arousal stimuli). Unexpected collapse is mediated through ventricular tachy arrhythmias such as polymorphic ventricular tachycardia (torsade de pointes) and ventricular fibrillation. Presently, there are three key LQTS genes (KCNQ1, KCNH2, and SCN5A) that provide explanation for approximately $75 \%$ of the disorder. For the major LQTS genotypes, genotype-phenotype correlations of gene-specific arrhythmogenic triggers, electrocardiogram (ECG) patterns, response to therapies, and intragenic and increasingly mutation-specific risk stratification. The 10 minor LQTS-susceptibility genes collectively account for less than 5\% of LQTS cases [72]. The key diagnostic and phenotypic hallmark of LQTS is abnormal prolongation of ventricular depolarization, measured as lengthening of the QT interval on the 12-lead ECG.

\section{Marfan Syndrome (MFS)}

Marfan syndrome (MFS) is a systemic connective tissue disorder with autosomal dominant inheritance, first showed in 1896 by Antoine Marfan. Life expectancy may be reduced, usually due to involvement of the cardiovascular system with progressive aortic root dilatation, dissection and rupture, or valvular regurgitation. The primary defect responsible for MFS, first described in 1991, resides in a gene (FBN1) localized to the long arm of chromosome 15 encoding the connective tissue protein fibrillin-1 [73]. Fibrillin is a structural glycoprotein component of microfibrils, which are extracellular components that participate in the formation of mature elastic fibers and which provide structural functions independent of elastin. Linkage analysis has shown no locus heterogeneity for MFS; the cause-and-effect relation with the clinical Marfan phenotype has been confined to fibrillin mutations [74].

\section{Molecular Diagnosis and Various Cancer}

The enigma of carcinogenesis has been now streamlined into few significant hallmarks such as sustaining proliferative signalling, evading growth suppressors, resisting cell death, enabling replicative immortality, inducing angiogenesis and activating invasion and metastasis. Underlying these hallmarks is genome instability, which generates the genetic diversity that expedites their acquisition. Thus persistent progress in molecular research has quite simplified the puzzle although its pathogenesis is still in infancy in various cancers. Cancer is a change in the cellular processes that cause a tumour to grow out of control. Cancerous cells sometimes have mutations in oncogenes, such as KRAS and CTNNB1 ( $\beta$-catenin) [75]. Analyzing the molecular signature of cancerous cells, the DNA and its levels of expression via messenger RNA enables physicians to characterize the cancer and to choose the best therapy for their patients. As of 2010, assays that incorporate an array of antibodies against specific protein marker molecules are an emerging technology; there are hopes for these multiplex assays that could measure many markers at once [76].

\section{Prostate Carcinoma}

Globally, prostate cancer (PCa) is one of the commonest cancers in men influencing $33 \%$ of global burden. The prostate biopsy remains invasive method for detecting $\mathrm{PCa}$ like others and currently, serum prostate-specific antigen (PSA) is considered as one of the best available tumour marker for detecting $\mathrm{PCa}$ at early stage which also has prognostic value. However, there are certain limitations of PSA in which the most significant one is that it is prostatespecific and not cancer specific.

\section{Genomics/Epigenetic and SNPs}

Over the past thirty years epigenetic has broadened its field and played a important role in the study of cancer genetics. Epigenetic gene regulation denotes to non-coded heritable changes in gene expression which includes DNA methylation, histone modifications and noncoding RNAinduced transcriptional changes. These are desirable for the transcriptional regulation and genomic stability. Two histone modifiers HAT p300 and HDM EZH2 are promising PCa biomarkers which have shown to be over expressed in PCa and its expression levels precisely linked with different disease stages. This characteristics may make it a standard dual biomarker. Hypermethylation and gene silencing have been documented for cell cycle regulation such as anaphase promoting complex (APC) and Ras association domaincontaining protein 1 (RASSF1a), detoxification enzymes e.g., glutathione S-transferase Pi 1 (GSTP1). Furthermore, combined assays for GSTP1 and APC hyper methylation have unlimited potential for detectingPCa in clinical samples up to $100 \%$ sensitivity. The risk of PCa can also be evaluated from single nucleotide polymorphisms (SNPs) of alleles in different region of chromosome (EHBP1, THADA, ITGA6, EEFSEC, PDLIM5, FU20032, SLC22A3, JAF1, LMTK2, NKX3, CMYC, MSMB, CTBP2, HNF1B, KLK2-3, TNRC6B, BIK, IL-10, IL-18 [77], NUDT10-11) which influence the behavior of the disease and its progression by changing expressions of mRNA and protein [78]. This has been explored and documented in more than 9000 patients (9893-61, 388 patients) [79]. 


\section{Transcriptomics}

The noncoding RNA (ncRNA) is a relatively novel field in PCa research. The term ncRNA encompasses the wellstudied functional RNAs like rRNA and tRNA, as well as microRNA (miRNA; previously known as small ncRNA) including long ncRNA (lncRNA) and small interfering RNA (siRNA). Three known lncRNAs which have validated their significance in detecting, screening and monitoring $\mathrm{PCa}$ [80], because of their high specificity and sensitivity are PCa non coding RNA-1 (PRNCR1), prostate-specific gene 1 (PSGEM1), and PCa antigen 3 (PCA3); also referred to as differential display 3 (DD3). Recently it has also been proposed that PCGEM1 gene, which encodes a lncRNA is highly prostate-specific. Moreover, the screening of TMPRSS2-ERG fusion (TEF) techniques as examined by Immunohistochemistry, FISH and RT PCR found to have significance in the diagnosis PCa. However the TE fusion in combination with PCA3 mRNA may prove more beneficial in diagnosis [81]. Circulating microRNAs (miRNA) have newly been supposed to be biomarkers for non-invasive diagnosis in various tumors [82]. Several gene expression studies also reported altered interleukins expressionin prostate cancer patients [83]. These differentially regulated miRNAs lead to changes in the expression and activity of their targets in PCa. The miRNA expression changes with the development and progression of $\mathrm{PCa}$ as some of the cancer-related genes are regulated by them and thus its dysregulation has significance in PCa. Using a mouse xenograft model, Mitchell et al. [84] have demonstrated that miRNAs originated from the human PCa xenografts enter the circulation and thus reported that miR-141 is up regulated in sera of metastatic $\mathrm{PCa}$ patients which can distinguish $\mathrm{PCa}$ patients from healthy controls with high sensitivity and more accuracy.

\section{Proteomics}

Proteomics also play a dynamic role in the field of biomarker specially in non-invasively collected bio fluids as for prognosis [CGRP, VEGF, endoglin (CD105), chromogranin-A, neuron-specific enolase, interleukin-6 transforming growth factor-b, other methylated genes including RASSF1a, APC, RARB2 and CDH1, prostate-specific cell antigen, testosterone, estrogen, sex hormone binding globulin, caveolin-1, E-cadherin, b-catenin, MMP-9, tissue inhibitor of MMPs (TIMP 1,2) progastrin-releasing peptide (ProGRP 31-98)] and PSP94, ZAG, prostasome (autoantibodies), huntingtin interacting protein 1 (auto-antibodies), TSP-1, leptin, ILGF-1, -2, human kallikrein 2, a-methylacyl-CoA racemase (auto-antibodies), early prostate cell antigen-1, -2, GSTP1 hypermethylation, cytokine macrophage MIF, hK11, apolipoprotein A-II for diagnosis. Few as urokinase-type plasminogen activator system, prostate membrane-specific antigen, hepatocyte growth factor, MIC-1, EGFR family (c-erbB-1 (EGFR), c-erbB-2 (HER2/neu), c-erbB-3 (HER3) and c-erbB-4 (HER4) [85], have shown their unique potency in diagnosis as well as prognosis [83]. More recently Dwivedi et al. [86-91] have proposed circulating serum interleukin-18 as a diagnostic biomarker and interleukin-10 for prognosis. Metastatic castration resistant PCa (MCRPCa) and metastasis associated protein-1 (MTA-1) have been widely explored for their role in PCa mainly in vascularization of the progressing tumor. The significance of WNT5A, EZH2, MAPK pathway members, AR, various androgen metabolism genes are also over expressed in metastatic $\mathrm{PCa}$ and c-FOS jun B down-regulated thus also have significance as biomarker. Other promising molecular markers for this cancer which are reportedly over expressed are human kallikrein-related peptidase 2 (hK2), early $\mathrm{PCa}$ antigen (EPCA), a-methylacyl-coA racemase (AMACR), insulinlike growth factors and binding proteins (IGFBP-2and IGFBP-3), TGF-b1, elevated circulating levels of the interleukin-6 (IL-6), and its receptors, urokinase plasminogen activator (UPA) and receptor (UPAR), enhancer of zeste homolog 2(EZH2), and prostate-specific membrane antigen (PSMA) [92].

\section{Breast Cancer}

Breast cancer is a foremost public health issue globally. The number of new cases of female breast cancer was 124.9 per 100,000 women per year. The number of deaths was 21.2 per 100,000 women per year. These rates are ageadjusted and based on 2010-2014 cases and deaths. (National Cancer Institute stats report https://seer.cancer.gov/ statfacts/html/breast.html). The more typical approach to breast cancer diagnostics via hormone receptor analysis is IHC. IHC involves the use of antibodies and enzymes, such as horseradish peroxidase, to stain tissue sections for the tumor antigens of interest. This analysis method can be performed on either frozen or formalin-fixed paraffin-embedded (FFPE) tissue, as well as on small amounts of tissue acquired in procedures such as core biopsies. IHC also has the advantage of not only determining the percentage of positive nuclei but also the intensity of staining in individual nuclei. Unfortunately, in addition to a lack of inter laboratory standardization of the IHC technique, the process for characterizing the positivity of either ER or PR staining is performed subjectively by a pathologist, thereby introducing variability in interpretation. Regardless of this subjectivity in staining intensity, IHC is by far the most common approach to evaluating hormone status in breast 
cancer today. Another major prognostic marker that is currently recommended for the evaluation of primary invasive breast cancer is the human epidermal growth factor receptor 2, also known as HER2. HER2 is an oncogene belonging to the EGF receptor (EGFR) family. Gene amplification of HER2 has been shown to occur in $10-40 \%$ of primary tumors and HER2 protein over expression is found in almost $25 \%$ of breast cancers [93].

\section{HERmark $^{\mathrm{TM}}$ Assay}

In an effort to expand the available methods of HER2/neu analysis, Monogram Biosciences has recently released the HERmark $^{\mathrm{TM}}$ breast cancer assay. This assay measures total HER2 protein (H2T) and functional HER2 homodimer (H2D) levels on the cell surface of FFPE breast cancer tissue. It practices a dual antibody system in which a fluorescent tag on one antibody is cleaved by a second antibody containing a photo-activated molecule. The fluorescent tags are then quantified using capillary electrophoresis (CE). HERmark reports whether a patient is HER2-negative, -positive or -equivocal based on quantified HER2 protein levels expressed as numeric values (HERmark, Monogram Biosciences, Inc. www.hermarkassay. com).

\section{Transcriptomics Based Biomarkers: Theros H/ISM and MGISM}

Theros H/ISM is a molecular diagnostic test that assesses the ratio of HOXB13:IL17BR gene expression as a predictor of clinical outcome for breast cancer patients treated with tamoxifen. A high level of expression of the two-gene ratio has been associated with tumor aggressiveness and failure to respond to tamoxifen [94]. Theros MGISM is an additional test that uses a five-gene expression index to stratify ER + breast cancer patients into high or low risk of recurrence by reclassifying grade2 (intermediate proliferative) tumors into grade 1-like or grade 3-like outcomes [95].

\section{Mamma Print ${ }^{\mathrm{TM}}$}

The Mamma Print test is a molecular diagnostic tool that evaluates a breast cancer patient's chance for tumor recurrence. The Mamma Print uses a 70-gene signature that has been reported to have independent prognostic value over clinicopathologic risk assessment in patients with node-negative breast cancer. The test needs a fresh sample (at least $3 \mathrm{~mm}$ in diameter) obtained during a surgical biopsy to be sent to the Agendia laboratory in Amsterdam in an RNA-stabilizing solution for analysis. RNA is isolated from the sample, amplified and hybridized with a standard reference to the Mamma Print microarray to obtain the 70-gene expression profile [96]. This method has been shown to have an extremely high correlation of prognostic prediction to tumor recurrence $(p<0.0001)$. In 2007, the US FDA approved the Mamma Print test for use on freshly frozen tissue. Although the Mamma Print gene expression profile has the potential to be a useful diagnostic tool, there are many limitations that need to be taken into consideration.

\section{Oncotype DX ${ }^{\circledR}$}

Oncotype DX is a 21-gene expression assay that uses qRTPCR and microarray technologies to characterize patients who may be positively treated with chemotherapy and estimate the likelihood that invasive breast cancer will recur after treatment. The Oncotype DX assay uses FFPE tissue blocks that can be shipped from anywhere in the USA and internationally. Currently, Oncotype DX is the standard breast cancer screening test for women with earlystage (Stage I or II), node-negative, ER + invasive breast cancer. The assay reports a recurrence score that ranges from 0 to 100 , indicating the probability of cancer recurring within 10 years of the original diagnosis. The recurrence score is then categorized into one of three groups: low, intermediate or high risk. There is a particular urgency for such information in women with early-stage breast cancer, where the great variety of treatment options can be narrowed down and tailored to each patient. Both ASCO and the National Comprehensive Cancer Network (NCCN) have incorporated the Oncotype DX assay into their guidelines [97].

\section{MicroRNA}

MicroRNA deregulation in breast cancer was primarily described by Iorio and colleagues in 2005. Since this first study, there has been a surge of data added on the expression of various microRNAs and their roles in breast cancer. miR-21 has surfaced in multiple studies as having consistent and significant increased expression in breast cancer cell lines and human tissue when compared with normal cells and tissues. Additionally miR-10b was one of the three microRNAs in the Iorio et al. study that demonstrated significant down regulation in breast cancer cells compared with primary human mammary epithelial cells (HMECs). However, in a successive study, miR-10b appeared to be highly expressed in metastatic cancer cells. 
Functional studies have described that miR-10b over expression promotes cell migration and invasion in vitro, and initiates tumor invasion and metastasis in vivo. Multiple studies have also demonstrated a significant association between expression of miR-206 and the expression of estrogen receptors in breast cancer. Iorio et al. [98] were the first to show that miR-206 expression was raised in those tumors that were ER. miR-125a and miR-125b were first reported in a microRNA profile study to be significantly down regulated in HER2-positive breast cancers. Computation analysis then confirmed target sites at the 3'UTR regions of HER2 and HER3 for these microRNAs. (Mattie et al. 2006) A tissue culture analysis showed that overexpression of miR-125a or miR-125b in an ErbB2dependent cancer cell line (SKBR3) suppressed HER2 and HER3 transcript and protein levels, which decreased cell motility and invasiveness [99]. Recent advancements and investigations in the field of liquid biopsy-based biomarkers, especially DTCs and CTCs bearing molecular signature have the capability to behave as potential biomarkers and can discriminate breast cancer between localized to metastasizing one. Further our current project SERBNPDF 2015/000322 DST, New Delhi also showing unique trends of various miRNA with cancer stem cells in breast cancer patients.

\section{Lung Cancer}

Lung cancer is the major cause of cancer-related death in the world. Non-small cell lung carcinoma (NSCLC) explains for $80-85 \%$ of all lung cancers, with lung adenocarcinoma being the most typical histologic type in the United States. Enhancements in our knowledge of molecular alterations at multiple levels (genetic, epigenetic, protein expression) and their functional importance have the potential to impact lung cancer diagnosis, prognostication and treatment. In lung cancer as in other malignancies, tumourigenesis narrates to activation of growth promoting proteins [e.g., v-Kiras2 Kirsten rat sarcoma viral oncogene homolog (KRAS), epidermal growth factor receptor (EGFR), BRAF, MEK-1, HER2, MET, ALK and rearranged during transfection (RET)] as well as inactivation of tumour suppressor genes [e.g., P53, phosphatase with tensin homology (PTEN), LKB-1 [100]. Lung cancers have extremely complex genomes with a recent large scale exome sequencing study of 31 non-small cell lung cancer (NSCLC) identifying 727 mutated genes not previously described in the literature or in the COSMIC database. Genomic studies have established previously well-known alterations in lung cancer such as KRAS, EGFR and BRAF and also identified low frequency but recurrent mutations that are novel in lung cancer including potentially targetable alterations in JAK2, ERBB4, RET, fibroblast growth factor receptor 1 (FGFR1), and discoidin domain receptor 2 (DDR2) [101]. Lung cancer mutations have been recognized in $\mathrm{v}$-Ki-ras2 Kirsten rat sarcoma viral oncogene homolog (KRAS), epidermal growth factor receptor (EGFR), BRAF and the parallel phosphatidylinositol 3-kinase (PI3 K) pathway oncogenes and more recently in MEK and HER2 while structural rearrangements in ALK, ROS1 and possibly rearranged during transfection (RET) provide new therapeutic targets. Amplification is another mechanism of activation of oncogenes such as MET in adenocarcinoma, fibroblast growth factor receptor 1 (FGFR1) and discoidin domain receptor 2 (DDR2) in SCC.

The role of tumour suppressor genes is increasingly recognized with aberrations reported in TP53, PTEN, RB1, LKB11 and p16/CDKN2A. The occurrence of these molecular targets as labelled above now defines the characteristics of NSCLC, with EGFR mutation and ALK rearrangements being the most clinically relevant at present. The prevalence of these mutations varies in lung cancer arising from patient in different regions. Activating EGFR mutations were found in up to $20 \%$ of Caucasians while in the Asian populations these EGFR mutations can be present in up to $40 \%$ of patients with NSCLC. These ethnic difference in NSCLC properties seems to be not limited to the presence of activating EGFR mutations but is also evident in other driver oncogenic mutation profiles (including ALK, KRAS, MET etc.), histology and hence tumour response to targeted therapy treatment. The presence of these driver mutations is normally found to be mutually exclusive to others in the same tumour [102]. In lung ADC among Asians, ALK rearrangement is seen in up to $7 \%$ of patients with lung ADC. Based on current reports of therapeutic molecular targets of EGFR mutation and ALK gene rearrangement in NSCLC and the availability of corresponding targeted agents, an algorithm of testing for molecular targets in NSCLC is proposed, which signifies a stepwise approach to testing for individual targets, beginning with EGFR then, if negative, ALK fusion gene or other potential targets if appropriate. Among NSCLC, adenocarcinoma accounts for up to $80 \%$ of histological subtypes. There are previous reports of correlations between histological subtypes of ADC demonstrating micropapillary features with presence of activating EGFR mutations, leading to the suggestions that the presence of specific mutations in NSCLC in fact represent heterogeneity in cancer biology and also response to therapy [103]. Given the heterogeneity of lung cancer histology, however, histological subtypes are hard to be used as the sole reliable marker for guidance to molecular phenotyping and selection of targeted therapy. Targeting therapeutic oncogenic mutations like EGFR and ALK can give dramatic initial treatment response or at least an initial stable clinical disease. 


\section{Oral Cancer}

Oral cancer is among the 10 most common cancers worldwide, and is particularly seen in disadvantaged elderly males. Early detection and quick treatment provide the best chance for cure. The most predictive of the molecular markers thus far available and assessed in OSCC development include the TSG p53 protein expression, chromosomal polysomy (DNA ploidy), and changes (termed loss of heterozygosity; LOH) in chromo-somes $3 p$ or $9 p$ (probably due to changes in the TSG p16). The practise of such biomarkers as adjuncts to routine histopatholoigical assessment may help prognostication and effective management of PMLs but their routine use is still hindered by the cost and complexity of the tests, the lack of facilities in some laboratories, and limited outcome studies to date. More readily available markers, such as those of cell proliferation (Ki-67 antigen) and apoptosis (Bax, Bcl-2), may also play a diagnostic role: apoptotic Bcl-2 expression de- creases significantly in dysplastic and early invasive lesions and then increases almost to normal tissue level in consequent stages while Ki-67 expression increases sharply in initial stages of OSCC, but significantly decreases in later stages [104].

The brush biopsy utilizes a small nylon brush to gather cytology samples then sent for computer scanning and analysis (Oral CDx) to identify and display individual cells. If suspect cells are identified, a pathologist then examines them to determine the final diagnosis and, in samples judged to be cancerous, a printout of the abnormal cells from the computer display and a written pathologist's report are returned to the clinician with the recommendation that a positive result be followed with a conventional incisional biopsy. The technique has proved rather controversial, with concern largely related to the question of false negative results. In the first published study, 59 of 945 patients in USA, the brush biopsy reportedly detected correctly all cases of OSCC, even when dentists did not suspect the presence of cancer from the lesion, but this trial showed a multi-center convenience sample, not all lesions were biopsied and inadequate specimens were excluded from the analysis. In a further US study, 61 brush biopsy results when compared with scalpel biopsy and histology to determine the positive predictive value of an abnormal brush biopsy finding showed that, of 243 patients with abnormal brush biopsies, 93 proved positive either for dysplasia [105] or carcinoma [106], and 150 were negative for either dysplasia or carcinoma, giving the positive predictive value of an abnormal brush biopsy of 38\% (93/243).

Promoter hyper-methylation patterns of TSG p16, O6methylguanine-DNA-methyltransferase, and death-associated protein kinase have been characterized in the saliva of head and neck cancer patients [107]. Forensic science has since shown that saliva can contain a number of messenger ribo-nucleic acid (mRNA) fragments including salivary specific statherin, histatin 3 , and the proline-rich proteins PRB1, PRB2 and PRB3, as well as the ubiquitously expressed spermidine N1 acetyl transferase (SAT), $\beta$-actin, and glyceraldehyde-3-phos-phate dehydrogenase (GAPDH). The mRNAs in saliva such as $\beta$-actin, SAT and interleukin- 8 are relatively stable despite the presence of salivary ribonucleases. mRNAs in saliva have been tested in over 300 saliva samples from OSCC patients and healthy people, and the signature was always present in higher levels in the saliva of OSCC patients than in saliva from healthy people, with an overall accuracy rate of about $85 \%$. Four salivary mRNAs (OLF/EBF associated zinc finger protein [OAZ], SAT, IL8, and IL1b) collectively have a discriminatory power of $91 \%$ sensitivity and specificity for OSCC detection [108]. Seven mRNA molecules: transcripts of: 1. IL8 (interleukin 8) playing a role in angiogenesis; replication; calcium-mediated signaling pathway; cell adhesion; chemotaxis; cell cycle arrest; immune response, 2. IL1B (interleukin 1B) which takes part in signal transduction; proliferation, inflammation and apoptosis 3 . DUSP1 (dual specificity phosphatase 1 ) with a role in protein modification; signal transduction and oxidative stress, 4. H3F3A (H3 histone, family 3A) having a DNA binding activity, 5. OAZ1 (ornithine decarboxylase antizyme 1) taking part in polyamine biosynthesis 6 . S100P (S100 calcium binding protein $\mathrm{P}$ ) with a role in protein binding and calcium ion binding, and 7. SAT (spermidine/ spermine N1-acetyltransferase) which takes part in enzyme and transferase activity were found significantly elevated in OSCC patients rather than in healthy controls [109].

Now, genetics has become the driving force in medical research and is now ready for integration into medical practice. Human genome draft (bio-informatics) with advancement in current techniques now opens new vistas in the fields of novel therapeutics such as Pharmacogenomics, Nutrigenomics that may transform the management of untreated disease and disorders [110-112].

\section{Personalized Medicine: An Integration of Diagnostics with Therapeutics}

In a large patient population size, a medicine and drug that is advantageous in many patients often flops to work in some other patients. Moreover, when it does work, it may cause adverse side effects, even death, in a small number of patients. Although large individual variability in drug efficacy and safety has been known to exist since the establishment of human medicine but the cause was beyond to knowledge. On the other hand, the request to 
overcome such variation has received more consideration now after the draft of human genome than ever before. The human genome sequence offers a special record of human evolution that varies among populations and individuals. Sequence variations in drug target proteins, drug-metabolizing enzymes, and drug transporters can alter drug efficacy, drug side effects, or both to cause variable drug responses in individual patients. From this prospect, the availability of the complete human genome sequence has made it possible to analyse the influence of variations of the human genome sequence on the pathogenesis of significant diseases and the response to drug therapy at an accelerating rate in recent years. The fast build-up of knowledge on genome-disease and genome-drug interactions has also encouraged the transformation of pharmacogenetics into a new entity of human genetics, pharmacogenomics and, at the same time, provided a rationale for the hope that individualized medicine can be achieved in the near future [113, 114].

The utilization of high throughput genotyping tools for the characterization and screening of single nucleotide polymorphisms (SNPs) ultimately can lead to the determination of the unique molecular signature of an individual in a relatively short period of time and it can predict the susceptibility or risk of any diseases. As The double mutation, A to T transversion at 1762 and $G$ to $A$ transition at 1764 , is often present in patients with chronic hepatitis, hepatocellular carcinoma, and hepatitis and less often in asymptomatic carriers, in immunosuppressed patients, and in carriers without HBV markers. Further, individual drug responses can be forecasted from known genetic variances correlated with a drug effect, like drug response of Maraviroc efficacy depends on CCR5 alleles in HIV-1 infections and Interferon-alpha drug efficacy also decided by the alleles of IL28B in Hepatitis C infections [115]. Thus, this will allow the physician to decide the patient with a selective drug treatment.

Few pharmaceutical companies and research development agencies are developing a precise haplotyping scheme to identify individuals/patients who will be benefiting from which type of drug in a particular disease and disorders. Further, Nutrigenomics is also evolving and promising a better management of patients. Several bioactive food components, including both essential and nonessential nutrients, can regulate gene expression patterns. Thus, nutrigenomics is providing the effects of ingested nutrients and other food components on gene expression and gene regulation, i.e. diet-gene interaction in order to spot the dietetic components having beneficial or detrimental health effects. Nutritional genomics (nutrigenomics), the junction between health, diet, and genomics, is influenced via epigenetic, transcriptomics, and proteomics processes of biology. Thus, it will help in determining the individual nutritional requirements based on the genetic makeup of the person (personalized diet) as well as the association between diet and chronic diseases like cancer, opening new vistas to understanding the complexity of various diseases [116].

\section{Conclusions}

In the upcoming years, molecular diagnostics will continue to be of critical importance to public health worldwide. Molecular diagnostic offers physicians with critical information based on the early exploration of pathogens and subtle changes in patients' genes and chromosomes, allowing for earlier diagnosis, selection of appropriate therapies and monitoring of disease progression. A wide range of molecular based tests is available to evaluate DNA difference and changes in gene expression of patient DNA and RNA through Real-Time PCR, FISH and Sequencing Technologies [117]. Further, the complex relationship between diseases like Fertility and Obesity or Metabolic syndrome with Cancer have also gained momentum due to exploration of common pathways, that only become possible of due to such advancement in molecular techniques [118]. However, there are many obstacles to overcome before the execution of these tests in clinical laboratories, such as which test to employ, the choice of technology and equipment, and issues such as cost-effectiveness, accuracy, reproducibility i.e. robustness, personnel training etc. Currently PCR-based testing outweigh; however, alternative technologies aimed to explore genome complexity without PCR are anticipated to gain momentum in the coming years as sequencing devices are more costly at present. Furthermore, development of integrated silicon chips mounted with biomolecules is now going to change the concept of traditional wet lab to "lab-on-a-chip". Thus it would be possible to analyse thousands of genes/proteins in hours from low amount/single cell sample. Thus coming era will be revolutionary, it will not only going to change our diagnostic systems but also plan of treatment and therapy [119, 120].

\section{References}

1. Kan YW, Lee KY, Furbetta M, Angius A, Cao A. Polymorphism of DNA sequence in the beta-globin gene region. Application to prenatal diagnosis of beta 0 thalassemia in Sardinia. N Engl J Med. 1980;302(4):185-8.

2. Persselin JE, Stevens RH. Anti-Fab antibodies in humans. Predominance of minor immunoglobulin $\mathrm{G}$ subclasses in rheumatoid arthritis. J Clin Invest. 1985;76(2):723-30.

3. Poste G. Molecular diagnostics: a powerful new component of the healthcare value chain. Expert Rev Mol Diagn. 2001;1(1):1-5. 
4. Mullis KB, Faloona FA. Specific synthesis of DNA in vitro via a polymerase-catalyzed chain reaction. Methods Enzymol. 1987;155:335-50.

5. Saiki RK, Gelfand DH, Stoffel S, Scharf SJ, Higuchi R, Horn GT, et al. Primer-directed enzymatic amplification of DNA with a thermostable DNA polymerase. Science. 1988;239(4839):487-91.

6. Saiki RK, Scharf S, Faloona F, Mullis KB, Horn GT, Erlich HA, et al. Enzymatic amplification of beta-globin genomic sequences and restriction site analysis for diagnosis of sickle cell anemia. Science. 1985;230(4732):1350-4.

7. Saiki RK, Bugawan TL, Horn GT, Mullis KB, Erlich HA. Analysis of enzymatically amplified beta-globin and HLA-DQ alpha DNA with allele-specific oligonucleotide probes. Nature. 1986;324(6093):163-6.

8. Higuchi R, Fockler C, Dollinger G, Watson R. Kinetic PCR analysis: real-time monitoring of DNA amplification reactions. Biotechnol Nat Publ Co. 1993;11(9):1026-30.

9. Mashal RD, Koontz J, Sklar J. Detection of mutations by cleavage of DNA heteroduplexes with bacteriophage resolvases. Nat Genet. 1995;9(2):177-83.

10. Saleeba JA, Ramus SJ, Cotton RG. Complete mutation detection using unlabeled chemical cleavage. Hum Mutat. 1992;1(1):63-9.

11. Landegren U, Kaiser R, Sanders J, Hood L. A ligase-mediated gene detection technique. Science. 1988;241(4869):1077-80.

12. Orita M, Iwahana H, Kanazawa H, Hayashi K, Sekiya T. Detection of polymorphisms of human DNA by gel electrophoresis as single-strand conformation polymorphisms. Proc Natl Acad Sci USA. 1989;86(8):2766-70.

13. Saiki RK, Walsh PS, Levenson $\mathrm{CH}$, Erlich HA. Genetic analysis of amplified DNA with immobilized sequence-specific oligonucleotide probes. Proc Natl Acad Sci USA. 1989;86(16):6230-4.

14. Chan K, Wong MS, Chan TK, Chan V. A thalassaemia array for Southeast Asia. Br J Haematol. 2004;124(2):232-9.

15. Fan J-B, Gunderson KL, Bibikova M, Yeakley JM, Chen J, Wickham Garcia E, et al. Illumina universal bead arrays. Methods Enzymol. 2006;410:57-73.

16. Sosnowski RG, Tu E, Butler WF, O'Connell JP, Heller MJ. Rapid determination of single base mismatch mutations in DNA hybrids by direct electric field control. Proc Natl Acad Sci USA. 1997;94(4):1119-23.

17. Ronaghi M, Uhlén M, Nyrén P. A sequencing method based on real-time pyrophosphate. Science. 1998;281(5375):363-5.

18. Rohde A, Hammerl JA, Appel B, Dieckmann R, Al Dahouk S. FISHing for bacteria in food: a promising tool for the reliable detection of pathogenic bacteria? Food Microbiol. 2015;46:395-407.

19. Cui C, Shu W, Li P. Fluorescence in situ hybridization: cellbased genetic diagnostic and research applications. Front Cell Dev Biol. 2016;4:89.

20. Shah J, Weltman H, Narciso P, Murphy C, Poruri A, Baliga S, et al. Dual color fluorescence in situ hybridization (FISH) assays for detecting Mycobacterium tuberculosis and Mycobacterium avium complexes and related pathogens in cultures. PLoS ONE. 2017;12(4):e0174989.

21. Nolte FS. Impact of viral load testing on patient care. Arch Pathol Lab Med. 1999;123(11):1011-4.

22. Woods GL. Molecular techniques in mycobacterial detection. Arch Pathol Lab Med. 2001;125(1):122-6.

23. Nübel U, Schmidt PM, Reiss E, Bier F, Beyer W, Naumann D. Oligonucleotide microarray for identification of Bacillus anthracis based on intergenic transcribed spacers in ribosomal DNA. FEMS Microbiol Lett. 2004;240(2):215-23.
24. Huang A, Li J-W, Shen Z-Q, Wang X-W, Jin M. Highthroughput identification of clinical pathogenic fungi by hybridization to an oligonucleotide microarray. J Clin Microbiol. 2006;44(9):3299-305.

25. Spiess B, Seifarth W, Hummel M, Frank O, Fabarius A, Zheng $\mathrm{C}$, et al. DNA microarray-based detection and identification of fungal pathogens in clinical samples from neutropenic patients. J Clin Microbiol. 2007;45(11):3743-53.

26. You Y, Fu C, Zeng X, Fang D, Yan X, Sun B, et al. A novel DNA microarray for rapid diagnosis of enteropathogenic bacteria in stool specimens of patients with diarrhea. J Microbiol Methods. 2008;75(3):566-71.

27. Sultankulova KT, Kozhabergenov NS, Strochkov VM, Burashev YD, Shorayeva KA, Chervyakova OV, et al. New oligonucleotide microarray for rapid diagnosis of avian viral diseases. Virol J. 2017;14(1):69.

28. Morita A. Clinical and Laboratory Diagnosis of Central Nervous System Infections. Brain Nerve Shinkei Kenkyu No Shinpo. 2015;67(7):777-85.

29. Dolan Thomas J, Hatcher CP, Satterfield DA, Theodore MJ, Bach MC, Linscott KB, et al. sodC-based real-time PCR for detection of Neisseria meningitidis. PLOS ONE. 2011;6(5):e19361.

30. Hoffman T, Rock K, Mugizi DR, Muradrasoli S, Lindahl-Rajala $\mathrm{E}$, Erume J, et al. Molecular detection and characterization of Brucella species in raw informally marketed milk from Uganda. Infect Ecol Epidemiol. 2016;6:32442.

31. Zarrinfar H, Mirhendi H, Fata A, Khodadadi H, Kordbacheh P. Detection of Aspergillus flavus and A. fumigatus in bronchoalveolar lavage specimens of hematopoietic stem cell transplants and hematological malignancies patients by realtime polymerase chain reaction, nested PCR and Mycological Assays. Jundishapur J Microbiol. 2015;8(1):e13744.

32. Jiang L, Ren H, Zhou H, Qin T, Chen Y. Simultaneous detection of nine key bacterial respiratory pathogens using Luminex $\mathrm{xTAG}^{\circledR}$ technology. Int $\mathrm{J}$ Environ Res Public Health. 2017;14(3):223.

33. Branson BM. The future of HIV testing. J Acquir Immune Defic Syndr 1999. 2010;55(Suppl 2):S102-5.

34. Fiebig EW, Wright DJ, Rawal BD, Garrett PE, Schumacher RT, Peddada L, et al. Dynamics of HIV viremia and antibody seroconversion in plasma donors: implications for diagnosis and staging of primary HIV infection. AIDS Lond Engl. 2003;17(13):1871-9.

35. Giachetti C, Linnen JM, Kolk DP, Dockter J, Gillotte-Taylor K, Park M, et al. Highly sensitive multiplex assay for detection of human immunodeficiency virus type 1 and hepatitis $\mathrm{C}$ virus RNA. J Clin Microbiol. 2002;40(7):2408-19.

36. Rouet F, Montcho C, Rouzioux C, Leroy V, Msellati P, Kottan $\mathrm{JB}$, et al. Early diagnosis of paediatric HIV-1 infection among African breast-fed children using a quantitative plasma HIV RNA assay. AIDS Lond Engl. 2001;15(14):1849-56.

37. Ford N, Nachega JB, Engel ME, Mills EJ. Directly observed antiretroviral therapy: a systematic review and meta-analysis of randomised clinical trials. Lancet Lond Engl. 2009;374(9707):2064-71.

38. Wang Z, Trillo-Pazos G, Kim S-Y, Canki M, Morgello S, Sharer LR, et al. Effects of human immunodeficiency virus type 1 on astrocyte gene expression and function: potential role in neuropathogenesis. J Neurovirol. 2004;10(Suppl 1):25-32.

39. Giri MS, Nebozhyn M, Showe L, Montaner LJ. Microarray data on gene modulation by HIV-1 in immune cells: 2000-2006. J Leukoc Biol. 2006;80(5):1031-43.

40. Liu D. Molecular approaches to the identification of pathogenic and nonpathogenic listeriae. Microbiol Insights. 2013;6:59-69. 
41. Boughner LA, Singh P. Microbial ecology: where are we now? Postdoc J J Postdr Res Postdr Aff. 2016;4(11):3-17.

42. Saldarriaga W, Tassone F, González-Teshima LY, ForeroForero JV, Ayala-Zapata S, Hagerman R. Fragile X syndrome. Colomb Medica Cali Colomb. 2014;45(4):190-8.

43. Amancio AP, de Melo CAO, de Vieira AM, Minasi LB, de Silva DME, da Silva CC, et al. Molecular analysis of patients suspected of fragile $\mathrm{X}$ syndrome. Genet Mol Res GMR. 2015;14(4):14660-9.

44. Tassone F. Advanced technologies for the molecular diagnosis of fragile $X$ syndrome. Expert Rev Mol Diagn. 2015;15(11):1465-73.

45. Maher ER. Von Hippel-Lindau disease. Curr Mol Med. 2004;4(8):833-42.

46. Crossey PA, Eng C, Ginalska-Malinowska M, Lennard TW, Wheeler DC, Ponder BA, et al. Molecular genetic diagnosis of von Hippel-Lindau disease in familial phaeochromocytoma. J Med Genet. 1995;32(11):885-6.

47. Hasani-Ranjbar S, Amoli MM, Ebrahim-Habibi A, Haghpanah V, Hejazi M, Soltani A, et al. Mutation screening of VHL gene in a family with malignant bilateral pheochromocytoma: from isolated familial pheochromocytoma to von Hippel-Lindau disease. Fam Cancer. 2009;8(4):465-71.

48. Elborn JS. Cystic fibrosis. Lancet Lond Engl. 2016;388(10059):2519-31.

49. Fanen P, Wohlhuter-Haddad A, Hinzpeter A. Genetics of cystic fibrosis: CFTR mutation classifications toward genotype-based CF therapies. Int J Biochem Cell Biol. 2014;52:94-102.

50. Chang EH, Zabner J. Precision genomic medicine in cystic fibrosis. Clin Transl Sci. 2015;8(5):606-10.

51. Langfelder-Schwind E, Karczeski B, Strecker MN, Redman J, Sugarman EA, Zaleski C, et al. Molecular testing for cystic fibrosis carrier status practice guidelines: recommendations of the National Society of Genetic Counselors. J Genet Couns. 2014;23(1):5-15.

52. Fuse N. Genetic bases for glaucoma. Tohoku J Exp Med. 2010;221(1):1-10.

53. Chen Y, Jiang D, Yu L, Katz B, Zhang K, Wan B, et al. CYP1B1 and MYOC mutations in 116 Chinese patients with primary congenital glaucoma. Arch Ophthalmol Chic Ill 1960. 2008;126(10):1443-7.

54. Dufier J-L, Rozet J-M, Kaplan J, Roche O. From congenital glaucoma to chronic open angle glaucoma in adulthood: a clinical and genetic continuum. Bull Acad Natl Med. 2013;197(1):133-9 (discussion 140-141).

55. Ratnapriya R, Chew EY. Age-related macular degenerationclinical review and genetics update. Clin Genet. 2013;84(2):160-6.

56. Velez-Montoya R, Oliver SCN, Olson JL, Fine SL, QuirozMercado H, Mandava N. Current knowledge and trends in agerelated macular degeneration: genetics, epidemiology, and prevention. Retina. 2014;34(3):423-41.

57. Daiger SP, Sullivan LS, Bowne SJ. Genes and mutations causing retinitis pigmentosa. Clin Genet. 2013;84(2):132-41.

58. Yeung KY, Baum L, Chan WM, Lam DS, Kwok AK, Pang CP. Molecular diagnostics for retinitis pigmentosa. Clin Chim Acta Int J Clin Chem. 2001;313(1-2):209-15.

59. Pang CP, Lam DSC. Differential occurrence of mutations causative of eye diseases in the Chinese population. Hum Mutat. 2002;19(3):189-208.

60. Collins SJ, Lawson VA, Masters CL. Transmissible spongiform encephalopathies. Lancet Lond Engl. 2004;363(9402):51-61.

61. Cancellotti E, Mahal SP, Somerville R, Diack A, Brown D, Piccardo P, et al. Post-translational changes to PrP alter transmissible spongiform encephalopathy strain properties. EMBO J. 2013;32(5):756-69.
62. Beekes M. Variant Creutzfeld-Jakob disease (vCJD): epidemiology and prevention from human to human secondary transmission. Bundesgesundheitsblatt Gesundheitsforschung Gesundheitsschutz. 2010;53(6):597-605.

63. Wadsworth JD, Joiner S, Hill AF, Campbell TA, Desbruslais M, Luthert PJ, et al. Tissue distribution of protease resistant prion protein in variant Creutzfeldt-Jakob disease using a highly sensitive immunoblotting assay. Lancet Lond Engl. 2001;358(9277):171-80.

64. Zanusso G, Polo A, Farinazzo A, Nonno R, Cardone F, Di Bari $\mathrm{M}$, et al. Novel prion protein conformation and glycotype in Creutzfeldt-Jakob disease. Arch Neurol. 2007;64(4):595-9.

65. Kramer ML, Bartz JC. Rapid, high-throughput detection of PrPSc by 96-well immunoassay. Prion. 2009;3(1):44-8.

66. Will RG. Variant Creutzfeldt-Jakob disease. J Neurol Neurosurg Psychiatry. 2002;72(3):285-6.

67. Salvadores N, Shahnawaz M, Scarpini E, Tagliavini F, Soto C. Detection of misfolded $A \beta$ oligomers for sensitive biochemical diagnosis of Alzheimer's disease. Cell Rep. 2014;7(1):261-8.

68. Zhang B, Gaiteri C, Bodea L-G, Wang Z, McElwee J, Podtelezhnikov AA, et al. Integrated systems approach identifies genetic nodes and networks in late-onset Alzheimer's disease. Cell. 2013;153(3):707-20.

69. Maron BJ, Maron MS. Hypertrophic cardiomyopathy. Lancet Lond Engl. 2013;381(9862):242-55.

70. Zou Y, Wang J, Liu X, Wang Y, Chen Y, Sun K, et al. Multiple gene mutations, not the type of mutation, are the modifier of left ventricle hypertrophy in patients with hypertrophic cardiomyopathy. Mol Biol Rep. 2013;40(6):3969-76.

71. Fujita E, Nakanishi T, Nishizawa T, Hagiwara N, Matsuoka R. Mutations in the cardiac troponin $\mathrm{T}$ gene show various prognoses in Japanese patients with hypertrophic cardiomyopathy. Heart Vessels. 2013;28(6):785-94.

72. Tester DJ, Ackerman MJ. Genetics of long QT syndrome. Method DeBakey Cardiovasc J. 2014;10(1):29-33.

73. Radke RM, Baumgartner H. Diagnosis and treatment of Marfan syndrome: an update. Heart $\mathrm{Br}$ Card Soc. 2014;100(17):1382-91.

74. Zeyer KA, Reinhardt DP. Engineered mutations in fibrillin-1 leading to Marfan syndrome act at the protein, cellular and organismal levels. Mutat Res, Rev Mutat Res. 2015;765:7-18.

75. Aftimos PG, Barthelemy P, Awada A. Molecular biology in medical oncology: diagnosis, prognosis, and precision medicine. Discov Med. 2014;17(92):81-91.

76. Harvey P, Basuita A, Endersby D, Curtis B, Iacovidou A, Walker M. A systematic review of the diagnostic accuracy of prostate specific antigen. BMC Urol. 2009;10(9):14.

77. Dwivedi S, Goel A, Khattri S, Mandhani A, Sharma P, Misra S, et al. Genetic variability at promoters of IL-18 (pro-) and IL-10 (anti-) inflammatory gene affects susceptibility and their circulating serum levels: an explorative study of prostate cancer patients in North Indian populations. Cytokine. 2015;74(1):117-22.

78. Ma Y, Li Y, Cui H, Liang X, Tang Z, Li X, et al. Re-evaluation of interval debulking surgery in advanced epithelial ovarian cancer. Zhonghua Fu Chan Ke Za Zhi. 2012;47(5):355-60.

79. Willard SS, Koochekpour S. Regulators of gene expression as biomarkers for prostate cancer. Am J Cancer Res. 2012;2(6):620-57.

80. Ross-Adams H, Ball S, Lawrenson K, Halim S, Russell R, Wells $\mathrm{C}$, et al. HNF1B variants associate with promoter methylation and regulate gene networks activated in prostate and ovarian cancer. Oncotarget. 2016;7(46):74734-46.

81. Tomlins SA, Aubin SMJ, Siddiqui J, Lonigro RJ, Sefton-Miller L, Miick S, et al. Urine TMPRSS2: ERG fusion transcript stratifies prostate cancer risk in men with elevated serum PSA. Sci Transl Med. 2011;3(94):94ra72. 
82. Srivastava A, Goldberger H, Afzal Z, Suy S, Collins SP, Kumar D. Detection of circulatory microRNAs in prostate cancer. Methods Mol Biol Clifton NJ. 2015;1238:523-38.

83. Dwivedi S, Goel A, Mandhani A, Khattri S, Sharma P, Misra S, et al. Functional genetic variability at promoters of pro-(IL-18) and anti-(IL-10) inflammatory affects their mRNA expression and survival in prostate carcinoma patients: five year follow-up study. Prostate. 2015;75(15):1737-46.

84. Mitchell PS, Parkin RK, Kroh EM, Fritz BR, Wyman SK, Pogosova-Agadjanyan EL, et al. Circulating microRNAs as stable blood-based markers for cancer detection. Proc Natl Acad Sci USA. 2008;105(30):10513-8.

85. Drake RR, Kislinger T. The proteomics of prostate cancer exosomes. Expert Rev Proteomics. 2014;11(2):167-77.

86. Dwivedi S, Goel A, Natu SM, Mandhani A, Khattri S, Pant KK. Diagnostic and prognostic significance of prostate specific antigen and serum interleukin 18 and 10 in patients with locally advanced prostate cancer: a prospective study. Asian Pac J Cancer Prev APJCP. 2011;12(7):1843-8.

87. Dwivedi S, Shukla KK, Gupta G, Sharma P. Non-invasive biomarker in prostate carcinoma: a novel approach. Indian J Clin Biochem IJCB. 2013;28(2):107-9.

88. Dwivedi S, Goel A, Khattri S, Mandhani A, Sharma P, Pant KK. Tobacco exposure by various modes may alter proinflammatory (IL-12) and anti-inflammatory (IL-10) levels and affects the survival of prostate carcinoma patients: an explorative study in North Indian population. Biomed Res Int. 2014;2014:158530.

89. Dwivedi S, Singh S, Goel A, Khattri S, Mandhani A, Sharma P, et al. Pro-(IL-18) and anti-(IL-10) inflammatory promoter genetic variants (intrinsic factors) with tobacco exposure (extrinsic factors) may influence susceptibility and severity of prostate carcinoma: a prospective study. Asian Pac J Cancer Prev APJCP. 2015;16(8):3173-81.

90. Dwivedi S, Goel A, Mandhani A, Khattri S, Pant KK. Tobacco exposure may enhance inflammation in prostate carcinoma patients: an explorative study in north Indian population. Toxicol Int. 2012;19(3):310-8.

91. Dwivedi S, Goel A, Khattri S, Sharma P, Pant KK. Aggravation of inflammation by smokeless tobacco in comparison of smoked tobacco. Indian J Clin Biochem IJCB. 2015;30(1):117-9.

92. Kattan MW, Eastham J. Algorithms for prostate-specific antigen recurrence after treatment of localized prostate cancer. Clin Prostate Cancer. 2003;1(4):221-6.

93. Krishnamurti U, Silverman JF. HER2 in breast cancer: a review and update. Adv Anat Pathol. 2014;21(2):100-7.

94. Zhao L, Zhu S, Gao Y, Wang Y. Two-gene expression ratio as predictor for breast cancer treated with tamoxifen: evidence from meta-analysis. Tumour Biol. 2014;35(4):3113-7.

95. Rajput AB, Hu N, Varma S, Chen C-H, Ding K, Park PC, et al. Immunohistochemical assessment of expression of centromere protein-A (CENPA) in human invasive breast cancer. Cancers. 2011;3(4):4212-27.

96. Buyse M, Loi S, van't Veer L, Viale G, Delorenzi M, Glas AM, et al. Validation and clinical utility of a 70-gene prognostic signature for women with node-negative breast cancer. J Natl Cancer Inst. 2006;98(17):1183-92.

97. Kip M, Monteban H, Steuten L. Long-term cost-effectiveness of Oncotype DX ${ }^{\circledR}$ versus current clinical practice from a Dutch cost perspective. J Comp Eff Res. 2015;4(5):433-45.

98. Iorio MV, Ferracin M, Liu C-G, Veronese A, Spizzo R, Sabbioni $\mathrm{S}$, et al. MicroRNA gene expression deregulation in human breast cancer. Cancer Res. 2005;65(16):7065-70.

99. Wang W, Luo Y. MicroRNAs in breast cancer: oncogene and tumor suppressors with clinical potential. J Zhejiang Univ Sci B. 2015;16(1):18-31.
100. Hensing T, Chawla A, Batra R, Salgia R. A personalized treatment for lung cancer: molecular pathways, targeted therapies, and genomic characterization. Adv Exp Med Biol. 2014;799:85-117.

101. Cancer Genome Atlas Research Network. Integrated genomic analyses of ovarian carcinoma. Nature. 2011;474(7353): 609-15.

102. Clamon GH, Bossler AD, Abu Hejleh T, Furqan M. Germline mutations predisposing to non-small cell lung cancer. Fam Cancer. 2015;14(3):463-9.

103. Black RC, Khurshid H. NSCLC: an update of driver mutations, their role in pathogenesis and clinical significance. RI Med J. 2015;98(10):25-8.

104. Gomes CC, Fonseca-Silva T, Galvão CF, Friedman E, De Marco L, Gomez RS. Inter- and intra-lesional molecular heterogeneity of oral leukoplakia. Oral Oncol. 2015;51(2):178-81.

105. Rosin MP, Poh CF, Guillard M, Williams PM, Zhang L, MacaUlay C. Visualization and other emerging technologies as change makers for oral cancer prevention. Ann N Y Acad Sci. 2007;1098:167-83.

106. Thomson PJ, Hamadah O. Cancerisation within the oral cavity: the use of "field mapping biopsies" in clinical management. Oral Oncol. 2007;43(1):20-6.

107. Rosas SL, Koch W, da Costa Carvalho MG, Wu L, Califano J, Westra W, et al. Promoter hypermethylation patterns of p16, O6-methylguanine-DNA-methyltransferase, and death-associated protein kinase in tumors and saliva of head and neck cancer patients. Cancer Res. 2001;61(3):939-42.

108. Rosin MP, Lam WL, Poh C, Le ND, Li RJ, Zeng T, et al. 3p14 and $9 \mathrm{p} 21$ Loss is a simple tool for predicting second oral malignancy at previously treated oral cancer sites. Cancer Res. 2002;62:6447-50.

109. Zimmermann BG, Wong DT. Salivary mRNA targets for cancer diagnostics. Oral Oncol. 2008;44(5):425-9.

110. Ahmed MU, Saaem I, Wu PC, Brown AS. Personalized diagnostics and biosensors: a review of the biology and technology needed for personalized medicine. Crit Rev Biotechnol. 2014;34(2):180-96.

111. Regierer B, Zazzu V, Sudbrak R, Kühn A, Lehrach H. Future of medicine: models in predictive diagnostics and personalized medicine. Adv Biochem Eng Biotechnol. 2013;133:15-33.

112. Dwivedi S, Yadav SS, Singh MK, Shukla S, Khattri S, Pant KK. Pharmacogenomics of Viral Diseases. In: Barh D, Dhawan D, Ganguly N, editors. Omics for personalized medicine. New Delhi: Springer; 2013. p. 637-76.

113. Dwivedi S, Goel A, Sadashiv, Verma A, Shukla S, Sharma P, et al. Molecular diagnosis of metastasizing breast cancer based upon liquid biopsy. In: Barh D, editor. Omics approaches in breast cancer. New Delhi: Springer; 2014. p. $425-59$.

114. Sharma P, Dwivedi S. Prospects of molecular biotechnology in diagnostics: step towards precision medicine. Indian J Clin Biochem IJCB. 2017;32(2):121-3.

115. Singh BP, Dwivedi S, Dhakad U, Murthy RC, Choubey VK, Goel A, et al. Status and interrelationship of zinc, copper, iron, calcium and selenium in prostate cancer. Indian J Clin Biochem IJCB. 2016;31(1):50-6.

116. Dwivedi S, Shukla S, Goel A, Sharma P, Khattri S, Pant KK. Nutrigenomics in breast cancer. In: Barh D, editor. Omics approaches in breast cancer. New Delhi: Springer; 2014. p. 127-51.

117. Dwivedi S, Khattri S, Pant KK. Recent advances in molecular diagnostic approaches for microbial diseases. In: Tiwari SP, Sharma R, Singh RK, editors. Recent advances in microbiology, vol. 1. New York: Nova; 2013. p. 133-54. 
118. Shukla KK, Chambial S, Dwivedi S, Misra S, Sharma P. Recent scenario of obesity and male fertility. Andrology. 2014;2(6):809-18.

119. Purohit P, Garg K, Singh V, Dwivedi S, Sharma P. Microalbuminuria in obese young and middle aged population: a potential marker of cardiovascular risk. Indian J Clin Biochem IJCB. 2016;31(3):349-52.
120. Dwivedi S, Samdariya S, Chikara G, Goel A, Pandey RK, Pareek P, et al. Molecular biotechnology for diagnostics applied molecular biotechnology. In: Khan IA, Barh D, Khan MS, editors. Applied molecular biotechnology. The next generation of genetic engineering. Florida: CRC Press; 2016. p. 303-43. 